\title{
Emerging therapies for idiopathic pulmonary fibrosis, a progressive age-related disease
}

\author{
Ana L. Mora ${ }^{1,2}$, Mauricio Rojas ${ }^{1,3}$, Annie Pardo $^{4}$, and Moises Selman ${ }^{5}$ \\ ${ }^{1}$ Division of Pulmonary, Allergy and Critical Care Medicine, Department of Medicine, E1246 BST, \\ 200 Lothrop Street, University of Pittsburgh, Pittsburgh, Pennsylvania 15213, USA \\ ${ }^{2}$ Vascular Medicine Institute, Department of Medicine, E1246 BST, 200 Lothrop Street, University \\ of Pittsburgh, Pittsburgh, Pennsylvania 15213, USA \\ ${ }^{3}$ Dorothy and Richard Simmons Center for Interstitial Lung Diseases, Division of Pulmonary, \\ Allergy, and Critical Care Medicine, Department of Medicine, W1244 BST, 200 Lothrop Street, \\ University of Pittsburgh, Pittsburgh, Pennsylvania 15213, USA \\ ${ }^{4}$ Facultad de Ciencias, Universidad Nacional Autónoma de México, Avenida Universidad 3000; \\ CP 04510, México City, Mexico \\ ${ }^{5}$ Instituto Nacional de Enfermedades Respiratorias Ismael Cosío Villegas, Tlalpan 4502; CP \\ 14080, México City, Mexico
}

\begin{abstract}
Idiopathic pulmonary fibrosis (IPF) is a fatal age-associated disease that is characterized by progressive and irreversible scarring of the lung. The pathogenesis of IPF is not completely understood and current therapies are limited to those that reduce the rate of functional decline in patients with mild-to-moderate disease. In this context, new therapeutic approaches that substantially improve the survival time and quality of life of these patients are urgently needed. Our incomplete understanding of the pathogenic mechanisms of IPF and the lack of appropriate experimental models that reproduce the key characteristics of the human disease are major challenges. As ageing is a major risk factor for IPF, age-related cell perturbations such as telomere attrition, senescence, epigenetic drift, stem cell exhaustion, loss of proteostasis and mitochondrial dysfunction are becoming targets of interest for IPF therapy. In this Review, we discuss current and emerging therapies for IPF, particularly those targeting age-related mechanisms, and discuss future therapeutic approaches.
\end{abstract}

Fibrosis as a pathogenic mechanism occurs in numerous organs and diseases. Fibrosis results from abnormal tissue repair and is associated with persistent and/or severe tissue damage and cellular stress. Epithelial and/or endothelial injury caused by various insults triggers interrelated wound-healing pathways to restore homeostasis ${ }^{1}$. Failure to adequately contain or eliminate inciting factors can exacerbate inflammation and chronic wound-

Correspondence to A.L.M. anamora@pitt.edu.

Competing interests statement

The authors declare competing interests: see Web version for details. 
healing responses, resulting in continued tissue damage and inadequate regeneration and, ultimately, fibrosis ${ }^{2}$. Although their aetiology and causative mechanisms differ, the various fibrotic diseases all have abnormal and exaggerated accumulation of extracellular matrix (ECM) components, mainly fibrillar collagens. The resulting fibrosis disturbs the normal architecture of affected organs, which ultimately leads to their dysfunction and failure. Nearly $45 \%$ of deaths in the developed world are attributable to some type of chronic fibroproliferative disease, including idiopathic pulmonary fibrosis (IPF) and end-stage fibrotic liver, kidney and heart disease ${ }^{2}$. The progressive nature of these diseases and the absence of effective treatments mean that a better understanding of the cellular and molecular mechanisms that contribute to the development of fibrosis is needed.

Although IPF was originally thought to be an inflammation-driven disorder, clinical trials with a combination of anti-inflammatory drugs (prednisone, azathioprine and $\mathrm{N}$-acetyl-Lcysteine (NAC)), failed to improve outcomes and instead increased mortality ${ }^{3}$. In 2014, two drugs, pirfenidone, a drug with poorly understood mechanisms, and nintedanib, a tyrosine kinase inhibitor, were approved for the treatment of IPF mainly on the basis of their ability to reduce the decrease in forced vital capacity (FVC) and to slow the pace of disease progression 4,5 . To date, however, it is unclear whether these drugs improve symptoms such as dyspnoea and cough, or whether their beneficial effect on functional decline translates to increased survival.

IPF results from a complex interplay of genetic and environmental risk factors, ageingassociated processes and epigenetic reprogramming, which result in profound changes to ALVEOLAR EPITHELIAL CELLS and FIBROBLASTS ${ }^{6}$. IPF is unique among the fibrotic diseases in that its prevalence is increased in older individuals and in patients with syndromes that promote a cellular ageing phenotype, such as people with mutations in telomerase components. Animal models have shown that with increased age or telomere attrition, the lungs become highly susceptible to injury and can develop progressive fibrosis without the need for repetitive injury ${ }^{7,8}$. Senescence and the senescence-associated secretory phenotype (SASP) have been postulated as key potential pathogenic mechanisms, as they are associated with ageing. Senescent epithelial cells secrete high levels of growth factors, cytokines, chemokines and matrix metalloproteinases that promote abnormal and persistent fibroblast activation and remodelling 9 . We also postulate that senescent fibroblasts secrete exaggerated levels of ECM components and are resistant to apoptosis, thereby promoting the accumulation of fibroblasts and the development of fibrosis. Mechanisms that are involved in the clearance of senescent cells might also be impaired in the ageing lung, leading to the persistence of fibrosis (FIG. $1)$.

IPF has multiple risk factors, including ageing and genetic alterations that enhance susceptibility to the disease, as well as exposure to compounds in the environment that potentially cause epithelial injury (FIG. 1). Cigarette smoke ${ }^{10,11}$, occupational exposures (such as from farming, livestock, and wood or metal dust) ${ }^{12}$ and viral infections (particularly human herpes viruses ${ }^{13}$ ) have all been linked to the development of IPF; whether this association is causative has not yet been proven. 
In this Review, we focus on current and emerging knowledge of the pathogenesis of IPF and on the potential role of ageing-related responses in lung cells. In addition, we discuss current and potential future therapeutic approaches for this age-related lung disease. The epidemiology, clinical presentation and diagnosis of IPF have recently been reviewed elsewhere ${ }^{14}$.

\section{Genetic susceptibility}

The most convincing evidence for genetic predisposition to IPF comes from a familial clustering of the disease, familial interstitial pneumonia (FIP), which accounts for at least 5$10 \%$ of all cases of $\mathrm{IPF}^{15-17}$. In addition, changes in gene sequence and variants in novel loci have been found to be associated with an increased risk of sporadic IPF.

\section{FIP}

Genetic mutations that contribute to FIP have been identified in only $30 \%$ of families with this condition, but mutations are found in genes with known biological roles in alveolar epithelial cells. Approximately 5\% of patients with FIP have mutations in genes encoding surfactant proteins, mainly pulmonary surfactant-associated protein C (SFTPC) and, less frequently, SFTPA2 (REFS 18-22). Mutations in the genes encoding these proteins result in the misfolding, misrouting and/or misprocessing of the protein, which provokes either toxicity and possible cell death, or cell activation and EPITHELIAL-MESENCHYMAL TRANSITION (EMT) in ALVEOLAR EPITHELIAL TYPE 2 Cells (AEC2s), which leads to a fibrotic response.

Several different mutations in telomerase components and genes associated with telomere biology have been reported in the $\sim 25 \%$ of FIP cases that result in abnormally short telomeres ${ }^{23-28}$. Importantly, telomere attrition has been found in leukocytes and AEC2s from patients with FIP, but also in some patients with sporadic IPF in which mutations have not been found in telomerase components ${ }^{29}$. Critically short telomeres activate a DNA damage response, which provokes cellular senescence or apoptosis ${ }^{30}$.

\section{Sporadic IPF}

Two recent genome-wide association studies (GWAS) have identified several specific gene variants that significantly increase the risk of developing $\operatorname{IPF}^{31,32}$. These genes are involved in epithelial cell-cell adhesion and integrity, the innate immune response, host defence and DNA repair.

The highest genetic risk factor for sporadic IPF is a common variant in the promoter region of $M U C 5 B$, which encodes a MUCIN involved in defence from pathogens in the airway, and is found in one-third of patients with IPF. Interestingly, the minor risk allele rs35705950 is also associated with familial $\mathrm{IPF}^{33}$. High expression of $M U C 5 B$ in the distal airway and honeycombed cysts in IPF lungs is associated with mucociliary dysfunction ${ }^{34}$. This observation is consistent with the idea that changes in the distal CONDUCTING AIRWAYS potentially enhance injury or disrupt repair responses in ALVEOLI. In keeping with this potentially crucial role of airway epithelial cells in the repair of the distal lung, single epithelial cell RNA sequencing in IPF lungs has identified some unique differentiation states and gene expression patterns, with many of these epithelial cells acquiring aberrant, multi- 
lineage-like states and some of them showing features of both conducting airway and alveolar epithelial cells ${ }^{35}$.

In addition to $M U C 5 B$, several variants of genes that participate in epithelial functions were found to increase the risk of IPF, including $D S P$, which encodes desmoplakin, an obligate component of DESMOSOMES, and $D P P 9$, which encodes dipeptidyl peptidase 9 , a protein that influences cell-ECM interactions, proliferation and apoptosis ${ }^{36}$. DSP expression in the lung declines with age, but transcript levels of $D S P$ are elevated in the IPF lung ${ }^{37}$. An intron 5 variant in $D S P$ was associated with a 2.3 -fold increase in the risk of $\operatorname{IPF}^{37}$.

Several common variants that influence telomere length have been associated with sporadic IPF, suggesting that alterations in telomere biology also have a role in this disease ${ }^{31}$. These variants are found in TERT, genomic regions near TERC and in OBFC1 (oligonucleotidebinding fold containing 1). Furthermore, 25-30\% of patients with sporadic IPF have substantially shorter telomeres in both leukocytes and AEC $2 \mathrm{~s}^{38}$. Moreover, a recent casecontrol, exome-wide collapsing analysis identified variants in TERT, RTEL1 and PARN as significant contributors to sporadic IPF ${ }^{39}$.

Three SNPs in the gene encoding toll-interacting protein (TOLLIP) were also identified by GWAS and two of these SNPs were associated with an increased risk of IPF ${ }^{32}$. TOLLIP is a regulator of the innate immune response and, importantly, decreases activity within the transforming growth factor $\beta 1$ (TGF $\beta 1$ ) signalling pathway ${ }^{40}$. Activation of the TGF $\beta 1$ pathway is thought to drive fibrosis (as discussed below).

\section{Genetic targets and therapies}

Gene therapy is a potential treatment for mutation-associated diseases, although it has so far been a formidable challenge to successfully apply it to clinical practice ${ }^{41,42}$. A potential strategy for gene therapy uses non-integrative and replication incompetent adenoviral vectors (AAVs). AAV9 has been used to deliver TERT in adult and aged mice, and increased the health span and longevity of mice without increasing the risk of developing cancer ${ }^{43}$. Another novel method is the targeted insertion of transgenes into particular chromosomal sites at which the transgenes can be stably and reliably expressed in all tissues of interest without adversely affecting endogenous gene structure or expression. The $C L Y B L$ gene on chromosome 13 has therapeutic potential as a 'safe harbour' locus in human cells: transgenes inserted at this location have high levels of expression, with less perturbation of local gene expression than genes incorporated into the AAVS1 locus, which is another common integration site ${ }^{44}$. CLYBL is a repeatedly recovered site of integration of AAVs in the genome of human cell lines ${ }^{44}$. In general, these therapeutic transgenes could be useful for human cell engineering, particularly for stem cell therapies, although safety has not yet been established. It will also be important to identify the alveolar epithelial stem or progenitor cells for this type of therapy in the lung.

\section{Alveolar epithelial cell activation}

There is extensive evidence that a dysfunctional alveolar epithelium, which is associated with mutations, stress and senescence, has a pivotal role in the aberrant injury-remodelling 
process that occurs in sporadic and familial IPF ${ }^{45}$. The increased fibroblast or MYOFIBROBLAST population is thought to drive fibrotic scarring and the destructive nature of the disease ${ }^{46}$.

From transcriptomic analyses, IPF epithelial cells have been shown to have a unique, aberrant phenotype that is characterized by the expression of markers of AEC1s, AEC2s and airway cells, and by the activation of multiple canonical pathways, including TGF $\beta 1$, HIPPO-YAP, p53, WNT and AKT-phosphoinositide 3-kinase (PI3K) ${ }^{35}$. Activated lung epithelial cells produce almost all of the mediators that induce the migration of mesenchymal cells of different origins (such as resident fibroblasts and FIBROCYTES), as well as their differentiation to myofibroblasts. These myofibroblasts, in turn, secrete excessive amounts of ECM components, mainly fibrillar collagens, thus destroying the lung architecture.

Platelet-derived growth factor (PDGF), TGF $\beta 1$, tumour necrosis factor (TNF), endothelin-1, connective tissue growth factor (CTGF), osteopontin and CXC chemokine ligand 12 (CXCL12) are all expressed by AEC2s and promote profibrotic responses ${ }^{46-53}$. Among these factors, AEC2-derived TGF $\beta 1$ is probably the strongest profibrotic mediator, and transduction of AECs with a retrovirus encoding activated TGF $\beta 1$ results in the remodelling of lung explants with interstitial fibrosis, expanded fibroblast populations, AEC2 hyperplasia and enlarged air spaces ${ }^{54}$. AEC2s are also able to activate the latent form of TGF $\beta 1$ through surface expression of integrin av $\beta 6$ (REFS 55,56).

Activated AEC2s inhibit angiogenesis and promote the activation of coagulation signalling pathways that are involved in wound healing. These cells inhibit angiogenesis through the expression of pigment epithelium-derived factor, which may explain the characteristic absence of capillaries in fibroblastic foci; AEC2s also affect the fibrin turnover by secreting tissue factor (TF) and plasminogen activator inhibitor 1 (PAI1) ${ }^{57,58}$. Coagulation factor $X$ $(\mathrm{FX})$, a central proteinase of the coagulation pathway, is also locally produced and activated by epithelial cells in IPF lungs ${ }^{59}$. FXa induces $a$-smooth muscle actin (aSMA) expression via a TGF $\beta 1$-dependent mechanism, promoting the differentiation of fibroblasts into myofibroblasts.

AEC2s from IPF lungs express markers of senescence and apoptosis, and replacing these cells might be key to tissue repair. Although the source of the cells that promote reepithelization and repair is uncertain, recent evidence has shown a marked increase in epithelial progenitor cell populations and the emergence of a KRT5 ${ }^{+} \mathrm{KRT}_{1} 4^{+} \Delta \mathrm{p} 63^{+}$(a p63 splice variant) epithelial population that is usually absent from healthy human lungs. KRT5 ${ }^{+}$ $\Delta \mathrm{p} 63^{+}$cells have persistent activation of the Notch signalling pathway and promote microhoneycombing rather than the regeneration of normal alveoli ${ }^{60}$. These data suggest that stressed AEC2s in the IPF lung are inefficient at regenerating the lung and that a second pool of progenitor cells mediates the repair response that favours honeycombing and fibrosis ${ }^{35,61}$.

Immunohistochemical evidence suggests that some epithelial cells are molecularly reprogrammed to undergo EMT $^{62,63}$. However, the contribution of this EMT-like process to the fibrotic response remains unresolved. Indeed, it is unclear whether epithelial cells can 
acquire enough mesenchymal characteristics to classify them as fibroblasts ${ }^{64}$. EMT and its reverse process, mesenchymal-epithelial transition (MET), are not all-or-none responses but are instead multi-state processes, with several intermediate, partial EMT phenotypes ${ }^{65}$. Activation of partial EMT may contribute to the breakdown of epithelial junction complexes, which enables programmed migration (a mesenchymal trait) and probably modifies the epithelial secretome profile in IPF lungs.

The regeneration of alveolar epithelial cells is one of the most important repair processes in many types of lung injury and could promote normal tissue architecture in lungs with IPF. However, most of our current knowledge of the molecular mechanisms in re-epithelialization and wound healing comes from studies in skin injury models and keratinocytes, and many of these processes are poorly characterized in the lungs.

\section{Therapies in clinical development}

Many of the therapeutic strategies that have reduced fibrosis in preclinical models have been assessed in humans. FIGURE 2 summarizes both the positive and the negative clinical trials for IPF that have been carried out. In many of these trials, the drugs were found to be ineffective or even potentially harmful. For example, negative results were obtained with interferon- $\gamma(\mathrm{IFN} \gamma)^{66}$, the TNF receptor inhibitor etanercept ${ }^{67}$, the endothelin receptor antagonists bosentan ${ }^{68}$ and macitentan ${ }^{69}$, the phosphodiesterase 5 inhibitor sildenafil ${ }^{70}$ and the chemotherapeutic drug imatinib mesylate ${ }^{71}$. As mentioned above, harmful effects were observed in studies using a triple therapy of prednisone, azathioprine and NAC ${ }^{3}$. Similarly, studies with the endothelin-1 receptor antagonist ambrisentan ${ }^{72}$, the anti-proliferative drug everolimus ${ }^{73}$ or the anti-coagulant warfarin ${ }^{74}$ resulted in a more rapid progression of the disease or in an increased risk of mortality. Only pirfenidone, a drug with a mechanism of action that has not been well-established, and nintedanib, an intracellular inhibitor that targets multiple tyrosine kinases including the receptors for vascular endothelial growth factor (VEGF), fibroblast growth factor (FGF) and PDGF, have been approved in the United States as disease-modifying therapies for IPF. Ongoing clinical trials for drug candidates for IPF, many of which have been published $66,67,69,71,72,75$, are summarized in TABLE 1, a selection of which are discussed in further detail below. In addition, several ongoing or recently completed clinical trials have been designed to alter IPF symptoms or comorbidities, which may improve pulmonary function and quality of life. For example, thalidomide (NCT00600028), IFNa (NCT01442779), PA101 (NCT02412020), gefapixant (also known as AF-219 and MK-7264; NCT02502097), omeprazole (NCT02085018) and azithromycin (NCT02173145) have been specifically used to improve chronic intractable cough, which is a particularly disturbing symptom of IPF. An ongoing clinical trial is also evaluating the effects of inhaled opiate therapy (fentanyl citrate) on dyspnoea, which is a severe symptom that is closely linked to poor perceived quality of life (NCT03018756).

A common complication of IPF that is strongly linked to mortality is the presence of pulmonary hypertension ${ }^{76}$. Drugs that target vascular reactivity and pulmonary arterial hypertension, such as inhaled nitric oxide (NCT01265888), losartan plus sildenafil (NCT00981747), BAY63-2521 (NCT00694850) and treprostinil (NCT02630316), have been tested in patients with IPF and pulmonary hypertension. A registered, but not yet open, study 
of antimicrobial therapy (co-trimoxazole or doxycycline) has been designed to influence clinical outcomes such as respiratory hospitalization and all-cause mortality (NCT02759120). Finally, a phase II open-label study is examining the effect of GBT440, an allosteric effector of sickle cell haemoglobin that increases the affinity of haemoglobin for oxygen, on hypoxaemia in patients with IPF (NCT02989168).

\section{Growth factors}

Mediators that are known to contribute to re-epithelialization include hepatocyte growth factor (HGF), fibroblast growth factor 1 (FGF1), keratinocyte growth factor (KGF; also known as FGF7), FGF10, TGFa and heparin-binding epidermal growth factor (HB-EGF) ${ }^{77}$. All of these mediators are ligands of tyrosine kinase receptors and usually stimulate epithelial cells to migrate, proliferate and survive. For example, HGF protects the lungs and prevents lung fibrotic remodelling in animal models ${ }^{78,79}$. Moreover, the administration of recombinant human HGF not only effectively suppressed collagen accumulation, but also ameliorated the fibrotic response if administered simultaneously or days after BLEOMYCININDUCED LUNG INJURY ${ }^{80}$. Similarly, one of the putative anti-fibrotic effects of mesenchymal stem cells (MSCs) on injured lungs occurs, at least partly, through the secretion of HGF or through the upregulation of the expression of endogenous HGF and prostaglandin E2 $\left(\mathrm{PGE}_{2}\right)^{79,81-83}$.

FGF1 has strong anti-fibrotic effects by inducing apoptosis, downregulating collagen expression and inhibiting or reversing TGF $\beta 1$-induced myofibroblast differentiation ${ }^{84,85}$. Moreover, transient upregulation of FGF1 markedly attenuated TGF $\beta 1$-induced lung fibrosis in rats when given either concomitantly or post-injury by enhancing AEC proliferation and hyperplasia ${ }^{86}$. In addition, mice engineered to inducibly overexpress FGF10 in the alveolar epithelium during both the inflammatory phase and the more clinically relevant fibrotic phase of the bleomycin injury model showed a strong attenuation of fibrotic scarring in the lungs ${ }^{87}$. Finally, KGF is a potent mitogenic factor for alveolar epithelial cells. Treatment with a KGF-expressing adenoviral vector reduced collagen deposition, improved lung function and reduced mortality in bleomycin-treated mice ${ }^{88}$. These changes occurred concomitantly with AEC proliferation, the suppression of TGF $\beta 1$ production and increased levels of surfactant proteins. The transplantation of bone marrow with an inducible gene transfer system that could deliver KGF in the lungs was also able to reduce bleomycininduced fibrosis ${ }^{89}$. In human volunteers, KGF treatment increased levels of surfactant protein D, a marker of AEC2 proliferation, in bronchiolar lavage samples and increased alveolar concentrations of mediators that drive epithelial repair and macrophage clearance of dead cells ${ }^{90}$.

\section{TGF $\beta$}

TGF $\beta 1$ is probably the most potent pro-fibrotic factor, and downregulation of the TGF $\beta$ pathway is an attractive target for IPF therapy. However, few candidates have reached even early phase clinical trials. In 2005, a pioneering phase I, open-label, single-dose (escalating) study evaluated whether fresolimumab (GC1008), a human monoclonal antibody that neutralizes TGF $\beta 1$, was safe for treating patients with IPF. This study was completed but, to our knowledge, the results were not published (NCT00125385). Fresolimumab has been

Nat Rev Drug Discov. Author manuscript; available in PMC 2018 April 30. 
administered in phase I trials in other clinical settings, for example, for treatment-resistant primary focal segmental glomerulosclerosis and advanced malignant melanoma or renal cell carcinoma ${ }^{91,92}$. More recently, and based on the activation of TGF $\beta 1$ downstream of av $\beta 6$ integrin, it has been suggested that pharmacological targeting of this receptor may have clinical utility ${ }^{55}$. Moreover, although av $\beta 6$ integrin expression is restricted to epithelial cells, myofibroblasts also express several av-containing integrins, and the mechanical force that is generated by the contractile actomyosin cytoskeleton and transmitted by integrins is a common mechanism for activating latent TGF $\beta 1$ (REF. 93). Accordingly, the deletion of the av integrin subunit from myofibroblasts or the use of a synthetic small-molecule inhibitor of all av-containing integrins (CWHM 12) effectively blocked the fibrotic response in multiple organs, including the lungs ${ }^{94}$. In this context, a phase I study designed to examine the safety and tolerability of a single nebulized dose of GSK3008348 (an integrin av antagonist) has recently begun in healthy volunteers, and the treatment will subsequently be tested in patients with IPF (NCT02612051). In addition, BG00011 (also known as STX-100), a humanized monoclonal antibody directed against av $\beta 6$ that is administered subcutaneously is being investigated in escalating doses to evaluate its safety and tolerability in the treatment of IPF (NCT01371305).

In addition, studies in preclinical models of lung fibrosis have shown encouraging results. For example, it was recently shown that BC-1485, a small molecule targeting the fibrosisinducing E3 ligase (FIEL1)-PIAS4 (protein inhibitor of activated STAT (signal transducer and activator of transcription) protein 4) pathway, which promotes TGF $\beta 1$ signalling, reduced the severity of fibrosis in bleomycin-induced lung injury 95 .

\section{$\mathrm{PGE}_{2}$}

Prostaglandin $\mathrm{G} / \mathrm{H}$ synthase 2 (encoded by $\mathrm{COX} 2$ ) and its enzymatic product $\mathrm{PGE}_{2}$ might have key roles in the phenotype of IPF fibroblasts. Fibroblasts derived from patients with IPF produce low levels of $\mathrm{PGE}_{2}$, an effect that is potentially secondary to epigenetic alterations in $C O X 2$ (REF. 96). $\mathrm{PGE}_{2}$ deficiency is believed to contribute to a reduced sensitivity to apoptosis and increased collagen production in fibroblasts ${ }^{75}$. However, studies of the putative effects of $\mathrm{PGE}_{2}$ in vivo are scant and have shown a protective effect but not a therapeutic effect ${ }^{97,98}$. Interestingly, $\mathrm{PGE}_{2}$-loaded liposomes administered by inhalation twice each week for 3 weeks beginning 1 day after bleomycin administration in mice markedly limited inflammation and fibrosis in the lungs ${ }^{99}$. Analogues of prostacyclin are an established therapy for patients with pulmonary hypertension, and current clinical trials in patients with pulmonary hypertension associated with interstitial lung disease, including combined pulmonary fibrosis and emphysema, are underway to determine safety and effectiveness (NCT02633293 and NCT02630316).

Combined therapies that target multiple pathogenic pathways simultaneously are a priority for future therapeutic strategies in IPF. In this context, a recent study using a multi-scale, hybrid, agent-based computational model in combination with experimental approaches indicated that simultaneously targeting epithelial cells and fibroblasts by reducing TGF $\beta 1$ and increasing $\mathrm{PGE}_{2}$ improves epithelial cell outcome and inhibits fibroblast activation, thus promoting healthy tissue repair better than the use of these approaches individually ${ }^{100}$. 


\section{Ageing mechanisms and novel therapies}

Ageing is an important risk factor for IPF and many of the main cellular perturbations described in ageing cells have been found in epithelial and mesenchymal lung cells from patients with IPF. How these processes interact and contribute to the pathogenesis of this disease is still unclear, but the identification of specific signalling pathways that can be targeted as novel therapeutic interventions is highly appealing and is beginning to be explored (FIG. 3).

\section{Telomere attrition}

Abnormal telomere shortening is frequently found in $\mathrm{IPF}^{24,27-29,38,101-104}$. However, the molecular mechanisms that link telomere dysfunction to the development of lung fibrosis are not well defined. Telomerase mutations have been associated with DNA damage and a senescent phenotype in AEC2s that diminishes their regenerative capacity ${ }^{29}$. Mouse models with telomere dysfunction in AEC2s develop a range of phenotypes depending on the telomerase defect. For example, mice deficient in telomerase reverse transcriptase (TERT), the catalytic subunit of telomerase, have normal telomere length and accumulate DNA damage only after a second 'hit' (REF. 7). The additive effect of low, repeated doses of bleomycin induces higher susceptibility to the development of lung fibrosis in TERTdeficient mice ${ }^{7}$. By sharp contrast, telomere shortening in AEC2s through the defective expression of telomeric repeat-binding factor 1 (TRF1) or TRF2 is associated with the agerelated development of lung fibrosis or the recruitment of inflammatory cells, respectively ${ }^{7,8,29}$. Mice deficient for TRF1 only in fibroblasts do not develop fibrosis ${ }^{8}$. These findings are a reminder that cell type and biological context could also affect how telomerase changes can drive age-related susceptibility to lung fibrosis.

\section{Targets and therapeutic interventions for telomere dysfunction}

In the past few years, several potential therapeutic strategies to restore or increase telomerase activity have been proposed. Particular emphasis has been placed on the potential use of oestrogen and androgens to induce TERT gene expression, based on the finding that mice deficient in aromatase in the adrenal gland showed substantial local inhibition of telomerase activity, shorter telomeres and adrenal atrophy ${ }^{105}$. The administration of oestrogen for 3 weeks restored telomerase activity and cell proliferation in oestrogen-deficient mice ${ }^{105}$. Importantly, androgens are reported to restore telomerase activity in lymphocytes from individuals with reduced telomerase function associated with TERT mutations ${ }^{106}$. Moreover, a patient with acquired aplastic anaemia owing to a TERT mutation was reported to respond to long-term androgen treatment with significant and sustained telomere elongation in haematopoietic stem cells and, consequently, in multilineage peripheral blood cells ${ }^{107}$. Based on this evidence, a phase I/II prospective non-randomized clinical trial was performed with the synthetic androgen danazol in 27 patients with short telomeres, most of whom had pulmonary fibrosis ${ }^{108}$. This pharmacological intervention resulted in an increase in telomere length, reaching a mean increase of 386 bp telomeric repeats by study completion. One caveat to this study is that telomere length was measured by PCR rather than by flow fluorescence in situ hybridization (flow-FISH), which is the preferred assay for this type of analysis. There are currently several clinical trials of this treatment in diseases associated 
with telomeropathies listed on ClinicalTrials.gov. One of these trials is an open-label study with nandrolone decanoate, an anabolic androgenic steroid; the trial is currently ongoing and targets several diseases that are characterized by abnormal telomere shortening, including IPF (NCT02055456). Importantly, a clinical trial in patients with DYSKERATOSIS CONGENITA (DKC) showed the same (or in some cases a shorter) telomere length after androgen therapy ${ }^{109}$. Severe secondary effects after longterm administration of androgenic steroids include peliosis hepatis, with life-threatening complications such as liver failure and spontaneous haemorrhage.

\section{Senescence and SASP}

Cell senescence is a crucial process that occurs in response to physiological signals during embryonic patterning and organogenesis, and that also occurs in pathological conditions that are associated with ageing and ageing-related diseases. Mouse models in which the reprogramming factors OCT4, SOX2, KLF4 and MYC are expressed in vivo show that injury favours senescence reprogramming in lung cells ${ }^{110}$. Moreover, senescent cells might be harmful and contribute to tissue remodelling, ageing and age-related diseases. In this context, alveolar epithelial and lung fibroblasts with a senescent phenotype are a prominent feature of IPF ${ }^{111-115}$.

Cellular senescence is a stress response that leads to permanent cell cycle arrest coupled with a complex secretory phenotype, known as SASP. The secretion of biologically active factors substantially contributes to the physiological and pathological effects of senescence in the organism. For example, SASP can promote wound healing by transiently providing growth factors such as TGF $\beta 1$ as well as initial inflammatory stimuli, including C-C motif chemokine 2 (CCL2), IL-6, IL-8 and IL-1a, which are required for tissue repair ${ }^{116}$. However, if present chronically, SASP drives pathological repair responses, which might contribute to fibrosis. Senescent cells are cleared effectively in young organisms; with age, the capacity to effectively eliminate senescent cells is reduced, which is potentially associated with immunosenescence.

Although some SASP factors are usually present in lungs with senescent phenotypes, the specific composition of SASP strongly depends on the cell type, the senescence-inducing stimuli and the diversity of the microenvironment, which together engender a phenotypic response that is highly context-dependent. The effects of SASP may be beneficial or harmful and we assume that, in the case of IPF, senescent epithelial cells are deleterious as they are likely to produce a plethora of profibrotic mediators. Similarly, senescent fibroblasts produce increased levels of ECM components, including collagen and fibronectin. Thus, 'antisenescence' therapies have emerged as promising strategies to selectively eliminate senescent cells or to attenuate the contribution of SASP.

\section{Targets and therapeutic interventions for senescence}

Cell senescence is an irreversible process; therefore, therapies have been designed to eliminate senescent cells and, in some cases, to reduce the induction of senescence or to attenuate SASP. Using a hypothesis-driven bioinformatics-based approach, two nonspecific and cell type-selective senolytic drugs were recently identified: dasatinib and quercetin ${ }^{117}$. 
Dasatinib is a drug that is approved by the US Food and Drug Administration (FDA) for the treatment of chronic myelogenous leukaemia and Philadelphia chromosome-positive acute lymphoblastic leukaemia, as it inhibits the chimeric breakpoint cluster region-Abelson tyrosine kinase (BCR-ABL) oncoprotein. It also inhibits ABL, SRC family kinases, KIT, platelet-derived growth factor receptor (PDGFR) and ephrin receptors, and reduces the expression of $\mathrm{p} 21$, PAI2 and BCL- $\mathrm{X}_{\mathrm{L}}$, so it consequently reduces the viability of senescent preadipocytes ${ }^{117}$. Quercetin is a natural flavonol that inhibits PI3K, other kinases and serpins, and selectively diminishes the viability of senescent endothelial cells. The combination of dasatinib and quercetin decreased the senescent cell burden in vivo in chronologically aged and progeroid mice, and improved cardiac function and reduced cardiac dysfunction caused by localized irradiation ${ }^{117}$. A combination therapy with dasatinib plus quercetin also induced the clearance of senescent cells and mitigated fibrosis in the INKATTAC MOUSE model if therapy was initiated 5 days after bleomycin treatment ${ }^{114}$. However, senolytic treatment with dasatinib and quercetin from week 2 to week 4 after bleomycin challenge reduced the expression of inflammatory markers but failed to attenuate fibrosis, as analysed by histopathology score or determined by functional lung compliance ${ }^{114}$. The same senolytic combination of dasatinib and quercetin effectively reduced senescence and SASP markers in isolated AEC2s from bleomycin-treated mice ${ }^{118}$.

Navitoclax (also known as ABT263; a specific inhibitor of the anti-apoptotic proteins BCL-2 and BCL- $\mathrm{X}_{\mathrm{L}}$ ) was also identified from a compound library as a selective, broadspectrum and potent killer of senescent fibroblasts and senescent epithelial cells in vitro ${ }^{119}$. To investigate this senolytic effect in vivo, young p16-3MR mice (which carry a trimodal reporter protein (3MR) under the control of the cyclin-dependent kinase inhibitor $2 \mathrm{~A}$ ), were exposed to a sublethal dose of radiation that induced a strong, time-dependent increase in the abundance of senescent cells. Navitoclax treatment effectively cleared these cells and also suppressed the expression of SASP ${ }^{120}$. Importantly, however, targeting BCL-2 family proteins is senolytic in some cell types but not in others, suggesting that senolytic drugs may have a cell type-restricted effect, underscoring the value of testing each cell type in a particular disease of interest during the senolytic drug development process ${ }^{119}$.

Fibroblasts from ageing mice exposed to bleomycin, as well as fibroblasts from IPF lungs, express high levels of NADPH oxidase 4 (NOX4) ${ }^{112}$. NOX4 has a crucial role in DNA damage and subsequent senescence. A dual inhibitor of NOX1 and NOX4 (GKT137831) has been shown to decrease reactive oxygen species (ROS) production and senescence markers in IPF fibroblasts. Additionally, in vivo knockdown of NOX4 reduced senescence in lung fibroblasts derived from ageing mice treated with bleomycin with substantially reduced collagen deposition. These data suggest that NOX4 inhibitors might also have senolytic effects $^{112,121}$. ROS generated by NOX4 have been implicated in the induction of cellular senescence; however, NOX4 also induces p53 protein expression and phosphorylation at Ser46, a critical event that regulates p53-dependent apoptosis and replicative senescence ${ }^{122,123}$. Increased expression levels of p53 and predicted activation of the p53mediated signalling pathway have been found in lung epithelial cells from IPF lungs ${ }^{124}$. Activation of the p53 pathway in the AEC2s of IPF lungs is also associated with high levels of PAI1. Deletion of PAI1 in AEC2s in mice protected these cells from bleomycin-induced 
senescence $^{125}$. Moreover, a small molecule PAI1 inhibitor (TM5275) blocked fibrosis in mice treated with bleomycin and protected AEC2s from senescence ${ }^{126}$.

There is growing evidence that the paracrine effects of the molecular pathways that regulate SASP can be manipulated ${ }^{127}$. However, most studies are at the early preclinical phase. Rapamycin, an inhibitor of mechanistic target of rapamycin (mTOR), markedly reduced the presence of a subset of SASP factors in senescent fibroblasts without reversing the senescence-induced growth arrest ${ }^{128}$. mTOR inhibition specifically downregulated MAP kinase-activated protein kinase 2 (MAPKAPK2, also known as MK2) activity, allowing the expression of ZFP36L1, an mRNA binding protein that targets many SASP components. Moreover, inhibiting mTOR with rapamycin increased the clonogenic capacity of primary human oral keratinocytes and their resident self-renewing cells by preventing stem cell senescence $^{129}$. As mentioned above, an inhibitor of mTOR is currently being studied in patients with IPF (NCT01462006), although in a previous trial another mTOR inhibitor, everolimus, seemed to worsen patient outcome, demonstrating that we are still far from using mTOR inhibitors in a clinical setting for $\mathrm{IPF}^{73}$.

Nuclear factor- $\kappa \mathrm{B}(\mathrm{NF}-\kappa \mathrm{B})$ pathway activation also modulates SASP. A screen of a kinase library revealed that kinases that activate NF- $\kappa \mathrm{B}$ have the strongest senescence-inducing effect and induction of SASP genes ${ }^{130}$. Interestingly, metformin, the effects of which include preventing NF- $\kappa$ B nuclear translocation, has been shown to reduce inflammation and oxidative stress and to promote health and increase lifespan in mice ${ }^{131,132}$. Activation of the Janus kinase (JAK)-STAT pathway has been found to lead to senescence and SASP, and inhibitors of this pathway have been shown to reprogramme SASP in adipocytes ${ }^{133}$. Importantly, IPF lung fibroblasts exhibit high STAT3 expression, and constitutively active STAT3 reduces proliferation and increases the expression of BCL- $\mathrm{X}_{\mathrm{L}}$ and BCL-2 in lung fibroblasts, suggesting that inhibitors of JAK-STAT might be useful to control senescence and SASP in IPF lungs ${ }^{134}$. Platelet-activating factor (PAF) is a SASP member that is secreted by senescent cells in lungs treated with bleomycin. Rupatadine, an antihistamine and inhibitor of PAF, has been shown to attenuate experimental lung fibrosis and improve lung function and survival, as well as reduce cellular senescence ${ }^{135}$. Rupatadine reduces the expression of CCAAT/enhancer-binding protein- $\beta$ (C/EBP $\beta)$, IL-6, CXCL2 and other SASP factors $^{135}$. These studies ${ }^{135}$ also suggest that rupatadine decreases p53-dependent senescence in bleomycin-injured lung tissues.

\section{Epigenetics and miRNAs}

The epigenome has a crucial role in determining gene expression patterns. The main epigenetic mechanisms include DNA methylation, histone modifications and non-coding RNAs; substantial crosstalk occurs between these modalities. Epigenetic modifications occur during ageing, are associated with environmental factors and are implicated in many complex age-related diseases. Importantly, some ageing-associated epigenetic changes (of which DNA methylation is the most commonly studied) are specific, whereas others are spontaneous and lead to fundamentally unpredictable differences in the epigenome between aged individuals ${ }^{136}$.

Nat Rev Drug Discov. Author manuscript; available in PMC 2018 April 30. 
A few studies of DNA methylation in IPF lungs have been carried out. In one study, involving 94 patients and 67 controls, 2,130 differentially methylated regions were identified genome-wide ${ }^{137}$. These differentially methylated regions included five trans-expression quantitative trait loci in which a methylation change provoked transcriptional modifications in a substantial number of genes. Among the most enriched canonical pathways were the CXCR4, thrombin, WNT- $\beta$-catenin and epithelial adherens junction signalling pathways. Interestingly, an analysis of binding motifs in the promoters of the 738 genes enriched for an expected inverse relationship between methylation and expression showed that regulators of lung development, specifically $\beta$-catenin, GLI1 and FOXC2, were overrepresented in this gene set, underscoring the role of developmental pathways in the pathogenesis of IPF ${ }^{138}$. Several targeted studies have identified epigenetic changes at the level of DNA methylation that influence the expression of genes that are likely to be involved in the pathogenesis of IPF, namely p14 (also known as ARF) ${ }^{139}$, aSMA ${ }^{140}$ and THY1 (also known as CD90) ${ }^{141}$.

Although there are few studies of histone modifications in IPF, the existing studies have provided some important clues about the decreased expression of certain anti-fibrotic genes. As discussed above, one of the most important downregulated molecules in IPF is $\mathrm{PGE}_{2}$. In this context, the defective $C O X 2$ gene transcription found in IPF fibroblasts was shown to be caused by deficient histone $\mathrm{H} 3$ and $\mathrm{H} 4$ acetylation, which resulted from decreased recruitment of histone acetyltransferase and increased recruitment of nuclear receptor corepressor (NCOR), co-repressor for RE1-silencing transcription factor (CoREST) and paired amphipathic helix protein SIN3A ${ }^{142}$. In addition, the gene encoding caveolin 1, an important regulator of TGF $\beta$ signalling, is actively silenced in IPF fibroblasts by epigenetic mechanisms that involve histone modifications, in particular H3K4Me3 (REF. 143). Histone deacetylation and increased $\mathrm{H} 3 \mathrm{~K} 9 \mathrm{Me} 3$ levels have also been identified as being responsible for the decreased expression of tumour necrosis factor receptor superfamily member 6 (TNFR6; also known as FAS) and resistance to TNFR6-mediated apoptosis in fibroblasts from fibrotic lungs, which could contribute to the reduced clearance of activated fibroblasts (discussed above) ${ }^{144}$. However, how these histone modifications influence the process of TNFR6 transcription in fibroblasts is unknown.

MicroRNAs (miRNAs) are short non-coding RNAs that are important epigenetic regulators of post-transcriptional events. Several miRNAs are dysregulated in IPF lungs and primarily affect epithelial cells and fibroblasts. For example, levels of hsa-miR-17-92, a crucial cluster for lung epithelial cell development and homeostasis and for effective lung repair, are substantially decreased in lungs from patients with IPF, as well as in lungs of bleomycintreated mice ${ }^{145}$. Let-7d is also downregulated in IPF lungs and may contribute to fibrosis by regulating the expression of high mobility group A2, which enhances $\mathrm{EMT}^{146}$. By contrast, the levels of the senescence-associated miRNAs miR-34a, miR-34b and miR-34c were increased in AEC2s from patients with IPF. Moreover, the upregulation of these miRNAs in lung epithelial cells was associated with a marked increase in senescence ${ }^{126}$. In fibroblasts, miR-21 expression is increased in myofibroblasts from IPF lungs and its inhibition mitigated the severity of bleomycin-induced lung fibrosis in mice; levels of miR-29 are simultaneously downregulated in these cells, which results in a coordinated increase in many ECM components ${ }^{147,148}$. Interestingly, evidence indicates that the decrease in miR-29 expression 
is regulated by fibrotic ECM via a positive feedback loop between fibroblasts and aberrant $\mathrm{ECM}^{149}$.

\section{Targets and therapeutic interventions for epigenetic changes}

Epigenetic therapy is in its infancy and has been primarily assessed in cancer; several new drugs are being tested and some have already been approved by the FDA ${ }^{150}$. One of the drugs that affects DNA methylation, $5^{\prime}$-azacytidine, is a potent demethylating agent that is FDA-approved for use in myelodysplastic syndromes and chronic myelomonocytic leukaemia, and it also reduces the fibrotic response in experimental models of fibrosis from several tissues, possibly by decreasing the expression of pro-fibrotic mediators ${ }^{151,152}$. Other inhibitors of DNA methyltransferases include guadecitabine, decitabine and zebularine, some of which are currently being tested in clinical trials for selected solid tumours ${ }^{153}$. However, it is important to emphasize the limitations of using general demethylating drugs, as this epigenetic process is crucial in normal physiology and nonselective demethylation may yield undesirable side effects. Moreover, azacytidine, for example, can also interfere with ribosomal RNA (rRNA), mRNA and tRNA synthesis, stability and function ${ }^{153}$.

The histone acetylation state is a crucial determinant of transcriptional regulation and, interestingly, the expression and activity of several class I and II histone deacetylases (HDACs) are upregulated in IPF lungs ${ }^{154}$. In this context, a number of HDAC inhibitors that chelate zinc from the active site of the deacetylase have been developed, several of which are currently approved by the FDA (primarily for cancer) ${ }^{153}$. Some HDAC inhibitors have been evaluated in experimental models of lung fibrosis with encouraging results. For example, vorinostat (suberoylanilide hydroxamic acid; SAHA), a pan-histone deacetylase inhibitor with FDA approval for the treatment of cutaneous $\mathrm{T}$ cell lymphoma, has been shown to induce the apoptosis of myofibroblasts from lungs with IPF in vitro, and to reduce the fibrotic response, thus improving lung function, in a murine model of bleomycin-induced pulmonary fibrosis ${ }^{155}$. More recently, it was found that vorinostat represses paraquatinduced lung fibrosis in rats by preventing the deacetylation of SMAD7 (a strong inhibitor of TGF $\beta 1$ signalling), highlighting the importance of non-histone targets of HDACs ${ }^{156}$. In addition, anti-fibrotic effects of valproic acid, an inhibitor of class I HDACs, have been reported in experimental models of numerous fibrotic conditions ${ }^{157}$. This drug suppresses TGF $\beta 1$-stimulated aSMA expression, probably by modulating SMAD expression, and is a potent inducer of autophagy ${ }^{158,159}$. More recently, several compounds with selectivity for individual HDACs, including HDAC1, HDAC3, HDAC6 and HDAC8, have been described ${ }^{160}$.

The use of miRNAs as therapeutic agents is attractive because a single miRNA can target several mRNAs within a biological pathway and therefore, theoretically, the modulation of one miRNA should influence an entire network and could modify a complex cell or disease phenotype. Several recent studies have shown that blocking upregulated lung 'fibromiRs' or restoring downregulated anti-fibromiRs markedly attenuates the lung fibrotic response. The administration of antisense probes that block miR-21 (an upregulated pro-fibrogenic miRNA) or the administration of mimics and/or the gene transfer of miR-200c or miR-29b (downregulated antifibrogenic miRNAs) have anti-fibrotic effects ${ }^{147,161-163}$. The intranasal 
delivery of miR-326 also mimics attenuated pulmonary fibrosis, probably by reducing levels of TGF $\beta 1$ and phosphorylated SMAD3 while upregulating levels of antifibrotic mRNAs, such as SMAD7 (REF. 164).

Interestingly, in a multicentre pilot study that aimed to assess long-term safety and clinical efficacy in patients with chronic hepatitis $\mathrm{C}$ virus infection, a miR-122-targeted therapy resulted in a prolonged decrease in viral RNA levels with no long-term safety issues after 35 months ${ }^{165}$. Therefore, targeting specific pathogenic miRNAs seems to be realistic in vivo and might be a future therapeutic option in IPF. However, this approach also faces substantial challenges, including nonspecific targets, redundancy and the need for tissuespecific delivery.

\section{Loss of proteostasis}

Abnormalities in protein folding, trafficking, processing and degradation induce endoplasmic reticulum (ER) stress and activate the adaptive unfolded protein response (UPR), which halts general protein synthesis and facilitates protein folding by increasing chaperone synthesis. Three distinct UPR signalling pathways exist in mammalian cells: the inositol-requiring protein 1 (IRE1), the pancreatic ER kinase (PERK) and the activating transcription factor 6 (ATF6) pathways.

High levels of markers of ER stress and UPR activation are found in alveolar epithelial cells of IPF lungs ${ }^{19,166}$. AEC2s from the zones of dense fibrosis lining fibrotic foci show the highest levels of ER stress markers and these cells colocalize with apoptotic markers ${ }^{166}$. Several potential causes of ER stress have been suggested. As discussed above, mutations and misfolding of surfactant protein $\mathrm{C}$ are found in some patients with FIP, whereas human herpesvirus infection may provoke ER stress in patients with sporadic IPF ${ }^{19}$. The elimination of excessive or misfolded proteins occurs through the ubiquitin proteosomal system and autophagy. Thus, alterations in these processes can exacerbate proteotoxic stress and can contribute to the pathogenesis of IPF. Dysfunction of the proteostatic network occurs with age and is potentially associated with the accumulation of oxidative, inflammatory and environmental exposures, which diminish the capacity of cells to compensate for abnormalities in the proteostasis network ${ }^{167,168}$.

\section{Targets and therapeutic interventions for insufficient proteostasis}

Therapeutic strategies to ameliorate proteostatic defects are being investigated in patients with diseases that are caused by defects in protein folding, including amyotrophic lateral sclerosis, Huntington disease and transthyretin-related amyloidosis, as well as metabolic diseases that are associated with ER stress, such as diabetes, and in patients with urea cycle disorders ${ }^{169-173}$. Loss-of-function diseases — including inherited genetic disorders with lung manifestations such as cystic fibrosis and lysosomal storage diseases - are currently treated by intravenous administration of wild-type proteins, a strategy that might be useful for cases of FIP that are associated with surfactant protein mutations. However, this therapeutic approach might have low efficacy, and alternative therapeutic strategies are under development. The administration of 'pharmacological chaperones', which stabilize the native conformation of a mutant enzyme and thus shift the folding balance away from 
degradation and aggregation, is being used in a clinical trial for lysosomal storage diseases (NCT00433147). Similarly, small molecules that stabilize the folded, functional state of a protein are being used in clinical trials to misassemble toxic amyloid aggregates ${ }^{174}$. Proteostasis can also be regulated by altering the composition of the chaperone network using small interfering RNAs (siRNAs) or compounds such as diltiazem and verapamil, both of which are $\mathrm{Ca}^{2+}$ channel blockers, to decrease intracytoplasmic $\mathrm{Ca}^{2+}$ levels. Decreased $\mathrm{Ca}^{2+}$ levels lead to increased transcription and translation of chaperones, including $78 \mathrm{kDa}$ glucose-regulated protein (also known as BiP) and HSP40, which enhance the folding, trafficking and activity of lysosomal enzymes ${ }^{175,176 .}$

One of the most promising investigational drugs that rescues mutant protein folding and promotes the clearance of toxic aggregates is the proteostasis regulator 4-phenyl butyric acid (4-PBA). Although 4-PBA has multiple activities - including inhibiting HDACs and scavenging ammonia - it also acts as an osmolyte chemical chaperone to rescue conformational abnormalities of proteins ${ }^{177}$. 4-PBA is reported to improve bleomycininduced lung fibrosis and to decrease the expression of ER stress markers, collagen and aSMA $^{178}$. Although targeting the ER stress response seems promising as a future therapy for lung diseases, there is limited knowledge of how to specifically control UPR pathways that activate both pro-survival adaptive responses and cell death. The development of small molecules that specifically target UPR signalling pathways will be of particular interest for future therapies in ER stress-related diseases ${ }^{179}$.

Autophagy can also relieve proteostatic stress. A reduced rate of autophagy has been found in IPF lungs, which could contribute to the trans-differentiation of fibroblasts into myofibroblasts and could promote senescence in lung epithelial cells. mTOR has a central role in promoting growth in the presence of nutrients and in maintaining low levels of autophagy. Insufficient autophagy and resistance to apoptosis are well-known hallmarks of IPF fibroblasts, and persistent activation of the mTORC1 pathway contributes to these changes ${ }^{180}$. Inducing apoptosis in IPF fibroblasts is a potential therapeutic approach, and in vitro studies suggest that apoptosis can be induced by co-treatment with two inhibitors of the mTOR signalling pathway, rapamycin and PP242 (REF. 180).

Clinical trials using mTOR inhibitors are ongoing in patients with IPF. A randomized, placebo-controlled, double-blind trial of GSK2126458 has recently been completed (NCT01725139). This drug is a highly selective pyridyl sulfonamide inhibitor of class I isozymes of PI3K and mTOR. However, as mentioned above, a clinical trial with an inhibitor of mTOR (everolimus) in patients with IPF worsened the disease ${ }^{73}$.

\section{Mitochondrial dysfunction}

Mitochondrial dysfunction contributes to the pathogenesis of several age-related diseases.

Age has been associated with decreased bioenergetic capacity, which is related to an increased number of mutations in the mitochondrial DNA (mtDNA), decreased mitochondrial biogenesis and increased levels of mitochondrial ROS, physiological signal molecules that can be detrimental at high levels. In IPF lungs, dysfunctional mitochondria have been found in AEC2s and lung fibroblasts. It is worth noting that mitochondrial dysfunction may contribute to DNA damage, senescence, SASP, telomere attrition, stem cell 
exhaustion, inflammation and other key age-related cell processes. Thus, therapies that target the mitochondria could be beneficial in treating many ageing-related impaired cellular functions ${ }^{181}$.

\section{Targets and therapeutic interventions for mitochondrial damage}

Mitochondria-targeted therapies have been developed to improve mitochondrial biogenesis, to activate mitophagy, to inhibit mitochondrial apoptosis, to scavenge toxic compounds and to bypass electron transport chain defects. Several strategies have been developed to target mitochondria with organelle-specific agents or prodrugs ${ }^{182}$. MitoQ, a ubiquinone conjugated to a lipophilic triphenylphosphonium cation that accumulates within mitochondria, is an antioxidant with radical scavenger properties that is currently in a clinical trial to examine whether it can improve the vascular, motor and cognitive physiological function of middleaged and older adults (NCT02597023). Importantly, although MitoQ has not shown efficacy in diminishing the progression of diseases such as Parkinson disease ${ }^{183}$, MitoQ has been shown to attenuate inflammation, necrosis and collagen deposition in animal models of liver fibrosis ${ }^{184}$. In addition, mitochondrially targeted antioxidants such as MitoQ substantially attenuated the expression of TGF $\beta 1$ and NOX4, two important mediators of myofibroblast differentiation, in fibroblasts derived from both normal and IPF lungs ${ }^{185}$. In support of the therapeutic potential of mitochondrial antioxidant agents in lung fibrosis, transgenic mice that express mitochondrial catalase are protected from asbestos- and bleomycin-induced lung fibrosis, and had lower levels of mitochondrial DNA damage ${ }^{186}$. Alternative strategies are actively being explored to improve mitochondrial targeting of antioxidant therapies. For example, small antioxidant molecules have been specifically targeted to the mitochondria by incorporating the Szeto-Schiller tetrapeptide sequence motif or the gramicidin S pentapeptide fragment. XBJ-5-131, an antioxidant that incorporates the mitochondrialtargeting peptide from gramicidin $\mathrm{S}$, has been shown to improve the survival of neurons in a mouse model of Huntington disease ${ }^{187}$.

Dysfunctional mitochondria in the AEC2s of IPF lungs have been associated with low expression of PTEN-induced putative kinase 1 (PINK1), a regulator of mitochondrial homeostasis and mitophagy. PINK1 accumulates on the surface of dysfunctional mitochondria where it simultaneously recruits and activates the E3 ubiquitin ligase activity of Parkin. Parkin ubiquitylates itself and other outer mitochondrial membrane proteins that serve as binding partners of p62, an adaptor molecule that interacts with LC3 to culminate in the engulfment of damaged mitochondria within autophagosomes for degradation ${ }^{188,189}$. PINK1 also has a crucial role in the maintenance of mitochondrial morphology and function, thus models of PINK1 deficiency result in impaired electron transport chain function, altered mitochondrial fusion-fission dynamics, increased oxidative stress and insufficient mitophagy ${ }^{190}$. Accordingly, mice that are deficient in PINK1 are more susceptible to the development of lung fibrosis using two models of lung fibrosis: bleomycin and $\gamma$ herpesvirus infection ${ }^{191,192}$. PINK1 expression decreases in the lung with age and ER stress, thus rendering this organ vulnerable to fibrosis. Interestingly, low expression of PINK1 in lung epithelial cells is associated with the increased secretion of active TGF $\beta 1$ and, in a potential negative feedback loop, TGF $\beta 1$ induces the expression of PINK1 in lung epithelial 
cells ${ }^{192}$. By contrast, in lung fibroblasts, TGF $\beta 1$ decreases PINK1 expression, which promotes myofibroblast differentiation ${ }^{193}$.

The E3 ubiquitin ligase Parkin is expressed at low levels in fibroblasts in IPF lungs ${ }^{194}$. Deficient mitophagy in Parkin-deficient fibroblasts mediates PDGFR-PI3K-AKT pathway activation and myofibroblast differentiation ${ }^{194}$. Confirming the crucial role of mitophagy in susceptibility to fibrosis, lung fibroblasts in which Parkin is knocked down show enhanced myofibroblast trans-differentiation and activation of pro-fibrotic signalling pathways ${ }^{194}$.

However, in a different set of studies, mice deficient in Parkin were found to be resistant to bleomycin-induced lung fibrosis ${ }^{195}$.

As PINK1 deficiency might be causally related to the mitochondrial dysfunction that is found in AEC2s of IPF lungs, neo-substrates that amplify the catalytic activity of PINK1 are potential therapies. One of these neo-substrates is kinetin, a precursor of kinetin triphosphate (KTP; also known as $\mathrm{N}^{6}$-furfuryl-ATP). Cells treated with kinetin accumulate KTP at levels that almost completely restore the wild-type activity of PINK1 in cells with mutant PINK1 (REF. 196). Dietary kinetin has proved effective in correcting neurodegenerative disorders associated with mutations in IKBKAP, which encodes a component of the I $\kappa \mathrm{B}$ kinase complex ${ }^{197}$. In vivo studies in mice have shown that oral dosing of kinetin can achieve effective concentrations of this neo-substrate in the plasma and even in the brain ${ }^{198}$. Thus, this approach to improve PINK1 activity is a potential therapeutic opportunity for cases of IPF that are associated with PINK1 deficiency.

It has also been suggested that SIRT3, a key mitochondrial NAD-dependent deacetylase, protects against injury and fibrosis. SIRT3 expression decreases with age, and mice deficient in SIRT3 develop spontaneous tissue fibrosis in multiple organs, including the lungs, with age ${ }^{199,200}$. SIRT3 expression is diminished in the skin and lungs of patients with systemic sclerosis $^{201}$, and mice deficient in SIRT3 are more susceptible than wild-type mice to bleomycin-induced lung fibrosis ${ }^{202,203}$. Two main mechanisms have been described as potential SIRT3-mediated protective mechanisms against fibrosis. First, SIRT3 has been shown to inhibit TGF $\beta 1$ signalling and to control myofibroblast transformation ${ }^{202}$. SIRT3 also regulates the acetylation and function of the mitochondrial DNA repair enzyme 8oxoguanine-DNA glycosylase-1 (OGG1) ${ }^{204,205}$. OGG1 hydrolyses oxidized guanine residues (8-Oxo-dG). Interestingly, OGG1 levels are reduced in SIRT3-deficient mice with a consequent increase in 8-Oxo-dG levels and mtDNA damage. Consistent with these data, mice overexpressing SIRT3 have sustained expression of OGG1, preserved mtDNA integrity and are protected from bleomycin-induced lung fibrosis ${ }^{203}$. As a therapeutic approach, mitochondria-targeted OGG1 has been shown to limit oxidant-induced mtDNA damage and lung injury ${ }^{205,206}$. SIRT3 is also regulated by levels of NAD. Interestingly, the decrease in SIRT3 activity has been associated at least in part with increased expression of the NADase CD38, the expression of which increases with age ${ }^{207}$. Boosting NAD levels has been shown to be an effective approach to protect against bleomycin-induced lung fibrosis, so novel CD38 inhibitors such as thiazoloquin(az)olin(on)es could be beneficial against lung fibrosis 208,209 . 
A pharmacological analogue of honokiol, known as hexafluoro, has been used to induce the expression of SIRT3 in lung fibroblasts stimulated with TGF $\beta 1$ and in mice treated with bleomycin ${ }^{201}$. Hexafluoro attenuated the TGF $\beta 1$-mediated induction of collagen 1, aSMA, and fibronectin expression. Similarly, hexafluoro treatment ameliorated bleomycin-induced skin and lung fibrosis in mice.

Taken together, the mitochondrial abnormalities in IPF lungs and the potential link with the pathobiology of the disease has opened up the possibility for new therapeutic approaches. As for other age-related lung diseases, the promotion of mitophagy and the control of mitochondrial oxidative stress and mtDNA damage are key processes that could be targeted therapeutically.

\section{Stem cell therapies}

MSCs have been proposed as a potential therapeutic for IPF because of their role in tissue repair and wound healing combined with their immuno-modulatory properties and immunoprivileged status ${ }^{210,211}$. After intravenous infusion, under normal conditions MSCs are first transiently retained in the lung, before migrating to the liver, spleen and other organs. For individuals with a lung injury, MSCs are retained in the lungs for longer ${ }^{212-214}$. In mice with bleomycin-induced lung fibrosis, MSCs have been found to exert a protective effect by ameliorating inflammation and by reducing the degree of injury and fibrosis ${ }^{210,215}$. MSCs produce soluble factors such as HGF, fibronectin, periostin, lumican and insulin-like growth factor-binding protein 7 (IGFBP7) that are implicated in epithelial repair.

\section{Targets and therapeutic interventions with MSCs}

There are two recently completed and several ongoing clinical trials to evaluate the safety and efficacy of MSCs in the treatment of IPF. A phase Ib clinical trial sponsored by The Prince Charles Hospital, Australia, to establish the feasibility and safety of intravenous administration of placenta-derived MSCs in patients with IPF was recently completed ${ }^{216}$. Eight patients diagnosed with moderately severe IPF were treated with either $1 \times 10^{6}$ or $2 \times$ $10^{6}$ MSCs per $\mathrm{kg}$ (NCT01385644). The patients were observed for 6 months, during which lung function was assessed through blood oxygenation, 6-minute walking distance (6 MWD) and high-resolution computed tomography imaging of the chest. At the end of the study, only minor adverse events were reported but there was no evidence of an effect on fibrosis. This study provides initial support for the short-term safety of intravenously delivered, placenta-derived MSCs to patients with moderately severe IPF. More recently, a group from the University of Miami, USA, reported the results from a phase Ib clinical trial in which bone marrow-derived MSCs were administered to nine patients divided into three groups, each of which received a different dose ${ }^{217}$. Patients were monitored for up to 60 weeks after cell infusion. The authors reported no complications or toxic effects. However, two patients from the group that received high doses died as consequence of complications of the disease. Of the patients that completed the study, there were no significant changes in pulmonary function or 6 MWD. Although these initial results are encouraging, at least regarding safety, MSCs have not yet been tested in trials statistically powered to determine efficacy, and many questions concerning the pathogenesis of IPF and the mechanisms of action of MSCs remain to be answered before MSCs will be useful for IPF therapy. 


\section{Concluding remarks}

IPF is a complex, age-related, epithelial-driven fibrotic lung disorder. The disease is progressive and lethal, usually within a few years of diagnosis, and limited therapeutic options exist. Only recently have two drugs that slow the progression of the disease been formally registered.

However, several meaningful pathogenic pathways have been recognized that have potential novel therapeutic targets that could be exploited. Research over the past 15 years has identified epithelial cells as fundamental in the pathogenesis of IPF, and these cells have a vast array of effects on fibroblasts and the surrounding extracellular matrix. Nevertheless, despite important advances in our understanding of normal regeneration and IPF tissue remodelling, and some encouraging results obtained in preclinical models, these findings have not led to substantial advances in patient therapy. Moreover, research into putative therapies for IPF is mainly focused on fibroblasts. No clinical trials addressing the aberrantly activated lung epithelium have been carried out, and most therapeutic research has focused on drugs that inhibit some of the multiple mediators that contribute to fibroblast migration, proliferation and differentiation into active myofibroblasts.

Single-agent therapies are likely to only have a moderate effect on IPF in a clinical setting because of the considerable redundancy of the components that participate in the aberrant repair process. For example, dual inhibition of PDGF and TGF $\beta 1$ was feasible and safe in a mouse model of radiation-induced lung injury, and substantially attenuated the fibrotic response, thereby extending survival compared with blockage of either pathway alone ${ }^{218}$. Preclinical studies and the subsequent clinical trials focus on single molecules, which help to identify mechanisms but which overlook the complexity of biological systems. In this context, multidrug approaches that target different mechanisms of the fibrogenic pathways, ideally by inhaled delivery, and the identification of subsets of patients who may respond better to specific drugs, are likely to be more effective. Importantly, there is some preliminary evidence suggesting that genetic architecture may influence response to therapy in patients with sporadic IPF. For example, it was recently shown that NAC seems to reduce clinically meaningful end point risks in patients carrying the rs3750920_TT genotype of TOLLIP $P^{219}$.

Although strong evidence supports the role of ageing as a risk factor for IPF, there are still some questions that need to be addressed. Importantly, the mechanisms that lead to SASP and senescence of epithelial cells and fibroblasts are uncertain. The identification of common and rare gene variants associated with the disease, as well as studies of epigenetic reprogramming and age-related molecular changes, have suggested novel therapeutic approaches, including eliminating senescent cells, attenuating SASP, manipulating miRNAs, improving mitochondrial function and proteostasis, and changing the patterns of DNA methylation and histone deacetylation.

Our understanding of the pathogenesis of IPF has advanced substantially, and we expect that in the near future innovative therapies will improve survival and quality of life in patients with this devastating disease. 


\section{Acknowledgments}

The authors thank E. Chiang for assistance and production of the figures. A.L.M. is funded by NIH R01 HL131789A; the Aging Institute, University of Pittsburgh; the Institute for Transfusion Medicine; and the Hemophilia Center for Western Pennsylvania. M.R. is funded by NIH R01 HL123766-01A1.

\section{Glossary}

\section{Alveolar epithelial cells}

The alveolar epithelium consists of alveolar epithelial type 1 cells (AEC1s) and type 2 cells (AEC2s). Squamous AEC1s are flat and constitute $~ 95 \%$ of the surface area of the lung but account for a minor proportion of the total cell population. AEC1s closely interact with the alveolar capillary system and are the primary site for gas exchange and the regulation of fluid homoeostasis.

\section{Fibroblasts}

Connective tissue cells of mesenchymal origin located in the lungs beneath epithelial cells or scattered throughout the interstitium between the epithelial and endothelial layers. They secrete extracellular matrix (ECM) proteins, especially fibrillar collagens. Fibroblasts and the ECM form the structural framework of tissues in animals and have a crucial role in tissue physiology and repair.

\section{Epithelial-mesenchymal transition}

(EMT). The biological process that allows differentiated epithelial cells to assume a mesenchymal phenotype, which includes enhanced migratory capacity and increased production of extracellular matrix components. This process has been associated with tissue repair, fibrosis and metastasis.

\section{Alveolar epithelial type 2 cells}

(AEC2s). Cuboidal cells scattered within the alveolar walls that synthesize and secrete the surfactant that regulates alveolar surface tension. AEC2s also regulate fluid balance, coagulation and fibrinolysis, and the immune response and host defence. AEC2s proliferate and differentiate into AEC1s, functioning as self-renewing cells and precursors of AEC1s, thus contributing to epithelial repair.

\section{Mucin}

Member of a family of gel-forming glycoproteins characterized by the presence of tandem repeat domains. Mucins are produced by epithelial cells and classified as membrane-bound or secreted. Mucins are the main component of mucus.

\section{Conducting airways}

The airways of the lung provide a pathway for bringing air to the gas exchange surfaces of the lung, but do not exchange gas. Mucins and host-defence molecules are secreted by submucosal glands into the periciliary fluids of the conducting airways, so they are important for defence against pathogens.

\section{Alveoli}


These structures are the ultimate unit of respiratory gas exchange and consist of a specialized epithelium surrounded by a rich network of pulmonary capillaries, embedded in a delicate meshwork of connective tissue.

\section{Desmosomes}

Intercellular tight junctions that provide a connection between intermediate filaments of the cytoskeletons of adjacent cells. These structures give strength to epithelial cells and contribute to resistance against shearing forces.

\section{Myofibroblast}

A cell type resulting from the differentiation of fibroblasts (and other mesenchymal cells) following injury, cellular distress or inflammation. Myofibroblasts are crucial for normal tissue wound repair but, under persistent or repeated insult, drive the accumulation of extracellular matrix and the disruption of the basement membrane, thus contributing to aberrant remodelling. In this context, myofibroblasts are key effector cells in fibrotic diseases.

\section{Fibrocytes}

Bone marrow-derived circulating cells that express both fibroblasts and leukocyte markers and produce components of the extracellular matrix.

\section{Bleomycin-induced lung injury}

Bleomycin is an anti-cancer therapy, the main complication of which is pulmonary fibrosis, and so bleomycin is widely used in experimental animal models of lung fibrosis as an intratracheal instillation or systemic injection. In mice, severe inflammation in days $0-7$ is followed by a progressive accumulation of collagen between days 14 and 21 after treatment.

\section{Dyskeratosis congenita}

(DKC). A disorder caused by mutations in the TERT, TERC, DKC1 or TINF2 genes, which are crucial for maintaining the structure and function of telomerase. The main clinical features vary widely, but include nail dystrophy, skin hyperpigmentation and oral leukoplakia. Patients with DKC have an increased risk of developing aplastic anaemia, cancer such as leukaemia and pulmonary fibrosis.

\section{Ink-Attac mouse}

Transgenic mouse model that removes $\mathrm{p} 16^{\text {Ink4a }}$-positive senescent cells upon the administration of the synthetic drug AP20187. Mice express a FK506-caspase 8 membranebound fusion protein, which is dimerized and activated by AP20187 binding, and is expressed under the control of the $p 16^{I N K 4 a}$ promoter.

\section{References}

1. Wynn TA, Ramalingam TR. Mechanisms of fibrosis: therapeutic translation for fibrotic disease. Nat. Med. 2012; 18:1028-1040. [PubMed: 22772564]

2. Wynn TA. Common and unique mechanisms regulate fibrosis in various fibroproliferative diseases. J. Clin. Invest. 2007; 117:524-529. [PubMed: 17332879]

3. Idiopathic Pulmonary Fibrosis Clinical Research Network. Prednisone, azathioprine, and N acetylcysteine for pulmonary fibrosis. N. Engl. J. Med. 2012; 366:1968-1977. This study clearly

Nat Rev Drug Discov. Author manuscript; available in PMC 2018 April 30. 
demonstrated that patients with IPF treated with a combination of prednisone, azathioprine and NAC have an increased risk of death and hospitalization, supporting the notion that IPF is not an inflammatory-driven disease. [PubMed: 22607134]

4. King TE Jr, et al. A phase 3 trial of pirfenidone in patients with idiopathic pulmonary fibrosis. N. Engl. J. Med. 2014; 370:2083-2092. This phase III study confirms and extends the findings that pirfenidone reduces disease progression in IPF patients with mild to moderate physiological impairment with an acceptable side-effect profile. [PubMed: 24836312]

5. Richeldi L, et al. Efficacy and safety of nintedanib in idiopathic pulmonary fibrosis. N. Engl. J. Med. 2014; 370:2071-2082. In both INPULSIS trials, it was shown that nintedanib, a potent kinase inhibitor blocking the effects of growth factors implicated in the pathogenesis of IPF, reduced the decline of FEV in patients with mild-to-moderate impairment of pulmonary function, which is consistent with a slowing of disease progression, and in general with tolerable adverse events. [PubMed: 24836310]

6. Selman M, Pardo A. Revealing the pathogenic and aging-related mechanisms of the enigmatic idiopathic pulmonary fibrosis. an integral model. Am. J. Respir. Crit. Care Med. 2014; 189:11611172. [PubMed: 24641682]

7. Povedano JM, Martinez P, Flores JM, Mulero F, Blasco MA. Mice with pulmonary fibrosis driven by telomere dysfunction. Cell Rep. 2015; 12:286-299. [PubMed: 26146081]

8. Naikawadi RP, et al. Telomere dysfunction in alveolar epithelial cells causes lung remodeling and fibrosis. JCI Insight. 2016; 1:e86704. [PubMed: 27699234]

9. Abbadie, C., Pluquet, O., Pourtier, A. Epithelial cell senescence: an adaptive response to precarcinogenic stresses?. Cell. Mol. Life Sci. 2017. http://dx.doi.org/10.1007/s00018-017-2587-9

10. Baumgartner KB, Samet JM, Stidley CA, Colby TV, Waldron JA. Cigarette smoking: a risk factor for idiopathic pulmonary fibrosis. Am. J. Respir. Crit. Care Med. 1997; 155:242-248. [PubMed: 9001319]

11. Steele MP, et al. Clinical and pathologic features of familial interstitial pneumonia. Am. J. Respir. Crit. Care Med. 2005; 172:1146-1152. [PubMed: 16109978]

12. Taskar VS, Coultas DB. Is idiopathic pulmonary fibrosis an environmental disease? Proc. Am. Thorac. Soc. 2006; 3:293-298. [PubMed: 16738192]

13. Stewart JP, et al. The detection of Epstein-Barr virus DNA in lung tissue from patients with idiopathic pulmonary fibrosis. Am. J. Respir. Crit. Care Med. 1999; 159:1336-1341. [PubMed: 10194186]

14. Richeldi L, Collard HR, Jones MG. Idiopathic pulmonary fibrosis. Lancet. 2017; 389:1941-1952. [PubMed: 28365056]

15. Fernandez BA, et al. A Newfoundland cohort of familial and sporadic idiopathic pulmonary fibrosis patients: clinical and genetic features. Respir. Res. 2012; 13:64. [PubMed: 22853774]

16. Garcia-Sancho C, et al. Familial pulmonary fibrosis is the strongest risk factor for idiopathic pulmonary fibrosis. Respir. Med. 2011; 105:1902-1907. [PubMed: 21917441]

17. Coghlan MA, et al. Sequencing of idiopathic pulmonary fibrosis-related genes reveals independent single gene associations. BMJ Open Respir. Res. 2014; $1: \mathrm{e} 000057$.

18. Mulugeta S, Nguyen V, Russo SJ, Muniswamy M, Beers MF. A surfactant protein C precursor protein BRICHOS domain mutation causes endoplasmic reticulum stress, proteasome dysfunction, and caspase 3 activation. Am. J. Respir. Cell Mol. Biol. 2005; 32:521-530. [PubMed: 15778495]

19. Lawson WE, et al. Endoplasmic reticulum stress in alveolar epithelial cells is prominent in IPF: association with altered surfactant protein processing and herpesvirus infection. Am. J. Physiol. Lung Cell. Mol. Physiol. 2008; 294:L1119-L1126. This report shows that ER stress and UPR activation are found in alveolar epithelial cells in the lungs of patients with sporadic and familial IPF and may contribute to its pathogenesis. [PubMed: 18390830]

20. Zhong Q, et al. Role of endoplasmic reticulum stress in epithelial-mesenchymal transition of alveolar epithelial cells: effects of misfolded surfactant protein. Am. J. Respir. Cell Mol. Biol. 2011; 45:498-509. [PubMed: 21169555]

21. Wang Y, et al. Genetic defects in surfactant protein A2 are associated with pulmonary fibrosis and lung cancer. Am. J. Hum. Genet. 2009; 84:52-59. [PubMed: 19100526] 
22. van Moorsel $\mathrm{CH}$, et al. SFTPA2 mutations in familial and sporadic idiopathic interstitial pneumonia. Am. J. Respir. Crit. Care Med. 2015; 192:1249-1252. [PubMed: 26568241]

23. Armanios MY, et al. Telomerase mutations in families with idiopathic pulmonary fibrosis. N. Engl. J. Med. 2007; 356:1317-1326. [PubMed: 17392301]

24. Tsakiri KD, et al. Adult-onset pulmonary fibrosis caused by mutations in telomerase. Proc. Natl Acad. Sci. USA. 2007; 104:7552-7557. References 23 and 24 demonstrate that mutations in the genes encoding telomerase components that result in telomere shortening confer an increase in susceptibility to adult-onset familial IPF. [PubMed: 17460043]

25. Kropski JA, et al. A novel dyskerin (DKC1) mutation is associated with familial interstitial pneumonia. Chest. 2014; 146:e1-e7. [PubMed: 24504062]

26. Alder JK, et al. Exome sequencing identifies mutant TINF2 in a family with pulmonary fibrosis. Chest. 2015; 147:1361-1368. [PubMed: 25539146]

27. Stuart BD, et al. Exome sequencing links mutations in PARN and RTEL1 with familial pulmonary fibrosis and telomere shortening. Nat. Genet. 2015; 47:512-517. [PubMed: 25848748]

28. Kannengiesser C, et al. Heterozygous RTEL1 mutations are associated with familial pulmonary fibrosis. Eur. Respir. J. 2015; 46:474-485. [PubMed: 26022962]

29. Alder JK, et al. Telomere dysfunction causes alveolar stem cell failure. Proc. Natl Acad. Sci. USA. 2015; 112:5099-5104. [PubMed: 25840590]

30. Deng Y, Chan SS, Chang S. Telomere dysfunction and tumour suppression: the senescence connection. Nat. Rev. Cancer. 2008; 8:450-458. [PubMed: 18500246]

31. Fingerlin TE, et al. Genome-wide association study identifies multiple susceptibility loci for pulmonary fibrosis. Nat. Genet. 2013; 45:613-620. This report is a large case-control GWAS and provides evidence that common genetic variations are important contributors to increased risk of idiopathic interstitial pneumonia. [PubMed: 23583980]

32. Noth I, et al. Genetic variants associated with idiopathic pulmonary fibrosis susceptibility and mortality: a genome-wide association study. Lancet Respir. Med. 2013; 1:309-317. [PubMed: 24429156]

33. Seibold MA, et al. A common MUC5B promoter polymorphism and pulmonary fibrosis. N. Engl. J. Med. 2011; 364:1503-1512. [PubMed: 21506741]

34. Yang IV, Fingerlin TE, Evans CM, Schwarz MI, Schwartz DA. MUC5B and idiopathic pulmonary fibrosis. Ann. Am. Thorac. Soc. 2015; 12(Suppl. 2):S193-S199. [PubMed: 26595739]

35. Xu Y, et al. Single-cell RNA sequencing identifies diverse roles of epithelial cells in idiopathic pulmonary fibrosis. JCI Insight. 2016; 1:e90558. This is an in depth transcriptome report of normal human AEC2s and IPF epithelial cells at the single-cell level. This study revealed a diversity of transcriptional 'states' of individual IPF cells, challenging the concept of precise epithelial cell identities. [PubMed: 27942595]

36. Zhang H, Chen Y, Keane FM, Gorrell MD. Advances in understanding the expression and function of dipeptidyl peptidase 8 and 9. Mol. Cancer Res. 2013; 11:1487-1496. [PubMed: 24038034]

37. Mathai SK, et al. Desmoplakin variants are associated with idiopathic pulmonary fibrosis. Am. J. Respir. Crit. Care Med. 2016; 193:1151-1160. [PubMed: 26669357]

38. Cronkhite JT, et al. Telomere shortening in familial and sporadic pulmonary fibrosis. Am. J. Respir. Crit. Care Med. 2008; 178:729-737. [PubMed: 18635888]

39. Petrovski S, et al. An exome sequencing study to assess the role of rare genetic variation in pulmonary fibrosis. Am. J. Respir. Crit. Care Med. 2017; 196:82-93. [PubMed: 28099038]

40. Zhu L, et al. Tollip, an intracellular trafficking protein, is a novel modulator of the transforming growth factor-beta signaling pathway. J. Biol. Chem. 2012; 287:39653-39663. [PubMed: 23027871]

41. Naldini L. Gene therapy returns to centre stage. Nature. 2015; 526:351-360. [PubMed: 26469046]

42. Somia N, Verma IM. Gene therapy: trials and tribulations. Nat. Rev. Genet. 2000; 1:91-99. [PubMed: 11253666]

43. Bernardes de Jesus B, et al. Telomerase gene therapy in adult and old mice delays aging and increases longevity without increasing cancer. EMBO Mol. Med. 2012; 4:691-704. [PubMed: 22585399]

Nat Rev Drug Discov. Author manuscript; available in PMC 2018 April 30. 
44. Cerbini T, et al. Transcription activator-like effector nuclease (TALEN)-mediated CLYBL targeting enables enhanced transgene expression and one-step generation of dual reporter human induced pluripotent stem cell (iPSC) and neural stem cell (NSC) lines. PLoS ONE. 2015; 10:e0116032. [PubMed: 25587899]

45. Selman M, et al. Idiopathic pulmonary fibrosis: prevailing and evolving hypotheses about its pathogenesis and implications for therapy. Ann. Intern. Med. 2001; 134:136-151. This is a seminal position paper that challenged the long-prevailing hypothesis that chronic inflammation has an essential role in the pathogenesis of IPF and proposed a new hypothesis highlighting the role of alveolar epithelial cells in the development of the disease. [PubMed: 11177318]

46. King TE Jr, Pardo A, Selman M. Idiopathic pulmonary fibrosis. Lancet. 2011; 378:1949-1961. [PubMed: 21719092]

47. Antoniades HN, et al. Platelet-derived growth factor in idiopathic pulmonary fibrosis. J. Clin. Invest. 1990; 86:1055-1064. [PubMed: 2170444]

48. Khalil N, O'Connor RN, Flanders KC, Unruh H. TGF-beta 1, but not TGF-beta 2 or TGF-beta 3, is differentially present in epithelial cells of advanced pulmonary fibrosis: an immunohistochemical study. Am. J. Respir. Cell. Mol. Biol. 1996; 14:131-138. [PubMed: 8630262]

49. Piguet PF, Ribaux C, Karpuz V, Grau GE, Kapanci Y. Expression and localization of tumor necrosis factor-alpha and its mRNA in idiopathic pulmonary fibrosis. Am. J. Pathol. 1993; 143:651-655. [PubMed: 8362967]

50. Saleh D, et al. Elevated expression of endothelin-1 and endothelin-converting enzyme-1 in idiopathic pulmonary fibrosis: possible involvement of proinflammatory cytokines. Am. J. Respir. Cell Mol. Biol. 1997; 16:187-193. [PubMed: 9032126]

51. Pan LH, et al. Type II alveolar epithelial cells and interstitial fibroblasts express connective tissue growth factor in IPF. Eur. Respir. J. 2001; 17:1220-1227. [PubMed: 11491168]

52. Andersson-Sjoland A, et al. Fibrocytes are a potential source of lung fibroblasts in idiopathic pulmonary fibrosis. Int. J. Biochem. Cell Biol. 2008; 40:2129-2140. [PubMed: 18374622]

53. Pardo A, et al. Up regulation and profibrotic role of osteopontin in human idiopathic pulmonary fibrosis. PLoS Med. 2005; 2:e251. [PubMed: 16128620]

54. Xu YD, et al. Release of biologically active TGF beta1 by alveolar epithelial cells results in pulmonary fibrosis. Am. J. Physiol. Lung Cell. Mol. Physiol. 2003; 285:L527-L539. [PubMed: 12598227]

55. Munger JS, et al. The integrin alpha v beta 6 binds and activates latent TGF beta 1: a mechanism for regulating pulmonary inflammation and fibrosis. Cell. 1999; 96:319-328. [PubMed: 10025398]

56. Horan GS, et al. Partial inhibition of integrin alpha(v) beta6 prevents pulmonary fibrosis without exacerbating inflammation. Am. J. Respir. Crit. Care Med. 2008; 177:56-65. [PubMed: 17916809]

57. Cosgrove GP, et al. Pigment epithelium-derived factor in idiopathic pulmonary fibrosis: a role in aberrant angiogenesis. Am. J. Respir. Crit. Care Med. 2004; 170:242-251. [PubMed: 15117744]

58. Kotani I, et al. Increased procoagulant and antifibrinolytic activities in the lungs with idiopathic pulmonary fibrosis. Thromb. Res. 1995; 77:493-504. [PubMed: 7624837]

59. Scotton CJ, et al. Increased local expression of coagulation factor $X$ contributes to the fibrotic response in human and murine lung injury. J. Clin. Invest. 2009; 119:2550-2563. [PubMed: 19652365]

60. Vaughan AE, et al. Lineage-negative progenitors mobilize to regenerate lung epithelium after major injury. Nature. 2015; 517:621-625. [PubMed: 25533958]

61. Smirnova NF, et al. Detection and quantification of epithelial progenitor cell populations in human healthy and IPF lungs. Respir. Res. 2016; 17:83. [PubMed: 27423691]

62. Willis BC, et al. Induction of epithelial-mesenchymal transition in alveolar epithelial cells by transforming growth factor beta1: potential role in idiopathic pulmonary fibrosis. Am. J. Pathol. 2005; 166:1321-1332. [PubMed: 15855634]

63. Kim KK, et al. Alveolar epithelial cell mesenchymal transition develops in vivo during pulmonary fibrosis and is regulated by the extracellular matrix. Proc. Natl Acad. Sci. USA. 2006; 103:13180 13185. [PubMed: 16924102] 
64. Rock JR, et al. Multiple stromal populations contribute to pulmonary fibrosis without evidence for epithelial to mesenchymal transition. Proc. Natl Acad. Sci. USA. 2011; 108:E1475-E1483. [PubMed: 22123957]

65. Nieto MA. Epithelial plasticity: a common theme in embryonic and cancer cells. Science. 2013; 342:1234850. [PubMed: 24202173]

66. King TE Jr, et al. Effect of interferon gamma-1b on survival in patients with idiopathic pulmonary fibrosis (INSPIRE): a multicentre, randomised, placebo-controlled trial. Lancet. 2009; 374:222228. [PubMed: 19570573]

67. Raghu G, et al. Treatment of idiopathic pulmonary fibrosis with etanercept: an exploratory, placebo-controlled trial. Am. J. Respir. Crit. Care Med. 2008; 178:948-955. [PubMed: 18669816]

68. King TE Jr, et al. BUILD-3: a randomized, controlled trial of bosentan in idiopathic pulmonary fibrosis. Am. J. Respir. Crit. Care Med. 2011; 184:92-99. [PubMed: 21474646]

69. Raghu G, et al. Macitentan for the treatment of idiopathic pulmonary fibrosis: the randomised controlled MUSIC trial. Eur. Respir. J. 2013; 42:1622-1632. [PubMed: 23682110]

70. Idiopathic Pulmonary Fibrosis Clinical Research Network. A controlled trial of sildenafil in advanced idiopathic pulmonary fibrosis. N. Engl. J. Med. 2010; 363:620-628. [PubMed: 20484178]

71. Daniels CE, et al. Imatinib treatment for idiopathic pulmonary fibrosis: randomized placebocontrolled trial results. Am. J. Respir. Crit. Care Med. 2010; 181:604-610. [PubMed: 20007927]

72. Raghu G, et al. Treatment of idiopathic pulmonary fibrosis with ambrisentan: a parallel, randomized trial. Ann. Intern. Med. 2013; 158:641-649. [PubMed: 23648946]

73. Malouf MA, Hopkins P, Snell G, Glanville AR. Everolimus in IPF Study Investigators. An investigator-driven study of everolimus in surgical lung biopsy confirmed idiopathic pulmonary fibrosis. Respirology. 2011; 16:776-783. [PubMed: 21362103]

74. Noth I, et al. A placebo-controlled randomized trial of warfarin in idiopathic pulmonary fibrosis. Am. J. Respir. Crit. Care Med. 2012; 186:88-95. [PubMed: 22561965]

75. Moore BB, et al. Alveolar epithelial cell inhibition of fibroblast proliferation is regulated by MCP-1/CCR2 and mediated by PGE 2. Am. J. Physiol. Lung Cell. Mol. Physiol. 2003; 284:L342L349. [PubMed: 12388376]

76. Klinger JR. Group III pulmonary hypertension: pulmonary hypertension associated with lung disease: epidemiology, pathophysiology, and treatments. Cardiol. Clin. 2016; 34:413-433. [PubMed: 27443138]

77. Gurtner GC, Werner S, Barrandon Y, Longaker MT. Wound repair and regeneration. Nature. 2008; 453:314-321. [PubMed: 18480812]

78. Dohi M, Hasegawa T, Yamamoto K, Marshall BC. Hepatocyte growth factor attenuates collagen accumulation in a murine model of pulmonary fibrosis. Am. J. Respir. Crit. Care Med. 2000; 162:2302-2307. [PubMed: 11112155]

79. Gazdhar A, et al. HGF expressing stem cells in usual interstitial pneumonia originate from the bone marrow and are antifibrotic. PLoS ONE. 2013; 8:e65453. [PubMed: 23840329]

80. Yaekashiwa M, et al. Simultaneous or delayed administration of hepatocyte growth factor equally represses the fibrotic changes in murine lung injury induced by bleomycin. A morphologic study. Am. J. Respir. Crit. Care Med. 1997; 156:1937-1944. [PubMed: 9412578]

81. Dong LH, et al. The anti-fibrotic effects of mesenchymal stem cells on irradiated lungs via stimulating endogenous secretion of HGF and PGE2. Sci. Rep. 2015; 5:8713. [PubMed: 25736907]

82. Gazdhar A, et al. The secretome of induced pluripotent stem cells reduces lung fibrosis in part by hepatocyte growth factor. Stem Cell Res. Ther. 2014; 5:123. [PubMed: 25384638]

83. Yoon YS, Lee YJ, Choi JY, Cho MS, Kang JL. Coordinated induction of cyclooxygenase-2/ prostaglandin E2 and hepatocyte growth factor by apoptotic cells prevents lung fibrosis. J. Leukoc. Biol. 2013; 94:1037-1049. [PubMed: 23922381]

84. Becerril C, et al. Acidic fibroblast growth factor induces an antifibrogenic phenotype in human lung fibroblasts. Am. J. Respir. Cell Mol. Biol. 1999; 20:1020-1027. [PubMed: 10226073]

85. Ramos C, et al. FGF-1 reverts epithelial-mesenchymal transition induced by TGF- $\{$ beta $\} 1$ through MAPK/ERK kinase pathway. Am. J. Phys. Lung Cell. Mol. Physiol. 2010; 299:L222-L231. 
86. Shimbori C, et al. Fibroblast growth factor-1 attenuates TGF beta1 induced lung fibrosis. J. Pathol. 2016; 240:197-210. [PubMed: 27425145]

87. Gupte VV, et al. Overexpression of fibroblast growth factor-10 during both inflammatory and fibrotic phases attenuates bleomycin-induced pulmonary fibrosis in mice. Am. J. Respir. Crit. Care Med. 2009; 180:424-436. [PubMed: 19498056]

88. Sakamoto $\mathrm{S}$, et al. Keratinocyte growth factor gene transduction ameliorates pulmonary fibrosis induced by bleomycin in mice. Am. J. Respir. Cell Mol. Biol. 2011; 45:489-497. [PubMed: 21131445]

89. Aguilar S, et al. Bone marrow stem cells expressing keratinocyte growth factor via an inducible lentivirus protects against bleomycin-induced pulmonary fibrosis. PLoS ONE. 2009; 4:e8013. [PubMed: 19956603]

90. Shyamsundar M, et al. Keratinocyte growth factor promotes epithelial survival and resolution in a human model of lung injury. Am. J. Respir. Crit. Care Med. 2014; 189:1520-1529. [PubMed: 24716610]

91. Trachtman H, et al. A phase 1, single-dose study of fresolimumab, an anti-TGF-beta antibody, in treatment-resistant primary focal segmental glomerulosclerosis. Kidney Int. 2011; 79:1236-1243. [PubMed: 21368745]

92. Morris JC, et al. Phase I study of GC1008 (fresolimumab): a human anti-transforming growth factor-beta (TGFbeta) monoclonal antibody in patients with advanced malignant melanoma or renal cell carcinoma. PLoS ONE. 2014; 9:e90353. [PubMed: 24618589]

93. Shi M, et al. Latent TGF-beta structure and activation. Nature. 2011; 474:343-349. [PubMed: 21677751]

94. Henderson NC, et al. Targeting of alphav integrin identifies a core molecular pathway that regulates fibrosis in several organs. Nat. Med. 2013; 19:1617-1624. [PubMed: 24216753]

95. Lear T, et al. Ubiquitin E3 ligase FIEL1 regulates fibrotic lung injury through SUMO E3 ligase PIAS4. J. Exp. Med. 2016; 213:1029-1046. [PubMed: 27162139]

96. Evans IC, et al. Epigenetic regulation of cyclooxygenase- 2 by methylation of c8orf4 in pulmonary fibrosis. Clin. Sci. (Lond.). 2016; 130:575-586. [PubMed: 26744410]

97. Dackor RT, et al. Prostaglandin E(2) protects murine lungs from bleomycin-induced pulmonary fibrosis and lung dysfunction. Am. J. Physiol. Lung Cell. Mol. Physiol. 2011; 301:L645-L655. [PubMed: 21856819]

98. Zhu Y, et al. A prostacyclin analogue, iloprost, protects from bleomycin-induced pulmonary fibrosis in mice. Respir. Res. 2010; 11:34. [PubMed: 20302663]

99. Ivanova $\mathrm{V}$, et al. Inhalation treatment of pulmonary fibrosis by liposomal prostaglandin E2. Eur. J. Pharm. Biopharm. 2013; 84:335-344. [PubMed: 23228437]

100. Warsinske HC, et al. Computational modeling predicts simultaneous targeting of fibroblasts and epithelial cells is necessary for treatment of pulmonary fibrosis. Front. Pharmacol. 2016; 7:183. [PubMed: 27445819]

101. Tsang AR, Wyatt HD, Ting NS, Beattie TL. hTERT mutations associated with idiopathic pulmonary fibrosis affect telomerase activity, telomere length, and cell growth by distinct mechanisms. Aging Cell. 2012; 11:482-490. [PubMed: 22364217]

102. Diaz de Leon A, et al. Subclinical lung disease, macrocytosis, and premature graying in kindreds with telomerase (TERT) mutations. Chest. 2011; 140:753-763. [PubMed: 21349926]

103. Silhan LL, et al. Lung transplantation in telomerase mutation carriers with pulmonary fibrosis. Eur. Respir. J. 2014; 44:178-187. [PubMed: 24833766]

104. Diaz de Leon A, et al. Telomere lengths, pulmonary fibrosis and telomerase (TERT) mutations. PLoS ONE. 2010; 5:e10680. [PubMed: 20502709]

105. Bayne S, et al. Estrogen deficiency leads to telomerase inhibition, telomere shortening and reduced cell proliferation in the adrenal gland of mice. Cell Res. 2008; 18:1141-1150. [PubMed: 18936784]

106. Calado RT, et al. Sex hormones, acting on the TERT gene, increase telomerase activity in human primary hematopoietic cells. Blood. 2009; 114:2236-2243. [PubMed: 19561322]

Nat Rev Drug Discov. Author manuscript; available in PMC 2018 April 30. 
107. Ziegler $\mathrm{P}$, et al. Telomere elongation and clinical response to androgen treatment in a patient with aplastic anemia and a heterozygous hTERT gene mutation. Ann. Hematol. 2012; 91:1115-1120. [PubMed: 22476886]

108. Townsley DM, et al. Danazol treatment for telomere diseases. N. Engl. J. Med. 2016; 374:19221931. [PubMed: 27192671]

109. Khincha PP, Wentzensen IM, Giri N, Alter BP, Savage SA. Response to androgen therapy in patients with dyskeratosis congenita. Br. J. Haematol. 2014; 165:349-357. [PubMed: 24666134]

110. Mosteiro L, et al. Tissue damage and senescence provide critical signals for cellular reprogramming in vivo. Science. 2016; 354:aaf4445. [PubMed: 27884981]

111. Minagawa S, et al. Accelerated epithelial cell senescence in IPF and the inhibitory role of SIRT6 in TGF-beta-induced senescence of human bronchial epithelial cells. Am. J. Physiol. Lung Cell. Mol. Physiol. 2011; 300:L391-L401. [PubMed: 21224216]

112. Hecker L, et al. Reversal of persistent fibrosis in aging by targeting Nox4 Nrf2 redox imbalance. Sci. Transl Med. 2014; 6:231ra247. Genetic and pharmacological targeting of NOX4 in ageing mice diminished the senescence of fibroblasts and reversed persistent fibrosis.

113. Yanai H, et al. Cellular senescence-like features of lung fibroblasts derived from idiopathic pulmonary fibrosis patients. Aging. 2015; 7:664-672. [PubMed: 26399448]

114. Schafer MJ, et al. Cellular senescence mediates fibrotic pulmonary disease. Nat. Commun. 2017; $8: 14532$. Studies using the bleomycin lung fibrosis model showed that deletion of $\mathrm{p} 16^{\mathrm{INK} 4}$ positive cells or the use of the senolytic cocktail dasatinib plus quercetin improved lung function and reduced the secretion of SASP factors. [PubMed: 28230051]

115. Alvarez, D., et al. IPF lung fibroblasts have a senescence phenotype. Am. J. Physiol. Lung Cell. Mol. Physiol. 2017. http://dx.doi.org/10.1152/ajplung.00220.2017

116. Rodier F, Campisi J. Four faces of cellular senescence. J. Cell Biol. 2011; 192:547-556. [PubMed: 21321098]

117. Zhu Y, et al. The Achilles' heel of senescent cells: from transcriptome to senolytic drugs. Aging Cell. 2015; 14:644-658. [PubMed: 25754370]

118. Lehmann M, et al. Senolytic drugs target alveolar epithelial cell function and attenuate experimental lung fibrosis ex vivo. Eur. Respir. J. 2017; 50:1602367. [PubMed: 28775044]

119. Zhu Y, et al. Identification of a novel senolytic agent, navitoclax, targeting the Bcl-2 family of anti-apoptotic factors. Aging Cell. 2016; 15:428-435. [PubMed: 26711051]

120. Chang J, et al. Clearance of senescent cells by ABT263 rejuvenates aged hematopoietic stem cells in mice. Nat. Med. 2016; 22:78-83. [PubMed: 26657143]

121. Jarman ER, et al. An inhibitor of NADPH oxidase-4 attenuates established pulmonary fibrosis in a rodent disease model. Am. J. Respir. Cell Mol. Biol. 2014; 50:158-169. [PubMed: 23977848]

122. Eid AA, et al. AMP-activated protein kinase (AMPK) negatively regulates Nox 4 dependent activation of p53 and epithelial cell apoptosis in diabetes. J. Biol. Chem. 2010; 285:3750337512. [PubMed: 20861022]

123. Feng L, Hollstein M, Xu Y. Ser46 phosphorylation regulates p53 dependent apoptosis and replicative senescence. Cell Cycle. 2006; 5:2812-2819. [PubMed: 17172844]

124. Kuwano K, et al. P21Waf1/Cip1/Sdi1 and p53 expression in association with DNA strand breaks in idiopathic pulmonary fibrosis. Am. J. Respir. Crit. Care Med. 1996; 154:477-483. [PubMed: 8756825]

125. Jiang, C., et al. Serpine 1 induces alveolar type II cell senescence through activating p53-p21-Rb pathway in fibrotic lung disease. Aging Cell. 2017. http://dx.doi.org/10.1111/acel.12643

126. Disayabutr S, et al. miR-34 miRNAs regulate cellular senescence in type II alveolar epithelial cells of patients with idiopathic pulmonary fibrosis. PLoS ONE. 2016; 11:e0158367. [PubMed: 27362652]

127. Malaquin N, Martinez A, Rodier F. Keeping the senescence secretome under control: molecular reins on the senescence-associated secretory phenotype. Exp. Gerontol. 2016; 82:39-49. [PubMed: 27235851]

128. Herranz N, et al. mTOR regulates MAPKAPK2 translation to control the senescence-associated secretory phenotype. Nat. Cell Biol. 2015; 17:1205-1217. [PubMed: 26280535]

Nat Rev Drug Discov. Author manuscript; available in PMC 2018 April 30. 
129. Iglesias-Bartolome R, et al. mTOR inhibition prevents epithelial stem cell senescence and protects from radiation-induced mucositis. Cell Stem Cell. 2012; 11:401-414. [PubMed: 22958932]

130. Ferrand M, et al. Screening of a kinase library reveals novel pro-senescence kinases and their common NF kappaB-dependent transcriptional program. Aging. 2015; 7:986-1003. [PubMed: 26583757]

131. Isoda K, et al. Metformin inhibits proinflammatory responses and nuclear factor-kappaB in human vascular wall cells. Arterioscler. Thromb. Vasc. Biol. 2006; 26:611-617. [PubMed: 16385087]

132. Martin-Montalvo A, et al. Metformin improves healthspan and lifespan in mice. Nat. Commun. 2013; 4:2192. [PubMed: 23900241]

133. Xu M, et al. JAK inhibition alleviates the cellular senescence-associated secretory phenotype and frailty in old age. Proc. Natl Acad. Sci. USA. 2015; 112:E6301-E6310. [PubMed: 26578790]

134. Pechkovsky DV, et al. STAT3 mediated signaling dysregulates lung fibroblast-myofibroblast activation and differentiation in UIP/IPF. Am. J. Pathol. 2012; 180:1398-1412. [PubMed: 22322297]

135. Lv XX, et al. Rupatadine protects against pulmonary fibrosis by attenuating PAF-mediated senescence in rodents. PLoS ONE. 2013; 8:e68631. [PubMed: 23869224]

136. Hannum G, et al. Genome-wide methylation profiles reveal quantitative views of human aging rates. Mol. Cell. 2013; 49:359-367. [PubMed: 23177740]

137. Yang IV, et al. Relationship of DNA methylation and gene expression in idiopathic pulmonary fibrosis. Am. J. Respir. Crit. Care Med. 2014; 190:1263-1272. This study identified methylationgene expression relationships within genes that are either involved in fibroproliferation or are probable candidates in this process. [PubMed: 25333685]

138. Selman M, Lopez-Otin C, Pardo A. Age-driven developmental drift in the pathogenesis of idiopathic pulmonary fibrosis. Eur. Respir. J. 2016; 48:538-552. [PubMed: 27390284]

139. Cisneros J, et al. Hypermethylation-mediated silencing of p14(ARF) in fibroblasts from idiopathic pulmonary fibrosis. Am. J. Physiol. Lung Cell. Mol. Physiol. 2012; 303:L295-L303. [PubMed: 22707614]

140. Hu B, Gharaee-Kermani M, Wu Z, Phan SH. Epigenetic regulation of myofibroblast differentiation by DNA methylation. Am. J. Pathol. 2010; 177:21-28. [PubMed: 20489138]

141. Sanders YY, et al. Thy-1 promoter hypermethylation: a novel epigenetic pathogenic mechanism in pulmonary fibrosis. Am. J. Respir. Cell Mol. Biol. 2008; 39:610-618. [PubMed: 18556592]

142. Coward WR, Watts K, Feghali-Bostwick CA, Knox A, Pang L. Defective histone acetylation is responsible for the diminished expression of cyclooxygenase 2 in idiopathic pulmonary fibrosis. Mol. Cell. Biol. 2009; 29:4325-4339. [PubMed: 19487460]

143. Sanders YY, et al. Epigenetic regulation of Caveolin-1 gene expression in lung fibroblasts. Am. J. Respir. Cell Mol. Biol. 2016; 56:50-61.

144. Huang SK, et al. Histone modifications are responsible for decreased Fas expression and apoptosis resistance in fibrotic lung fibroblasts. Cell Death Dis. 2013; 4:e621. [PubMed: 23640463]

145. Dakhlallah D, et al. Epigenetic regulation of miR-17 92 contributes to the pathogenesis of pulmonary fibrosis. Am. J. Respir. Crit. Care Med. 2013; 187:397-405. [PubMed: 23306545]

146. Pandit KV, et al. Inhibition and role of let-7d in idiopathic pulmonary fibrosis. Am. J. Respir. Crit. Care Med. 2010; 182:220-229. [PubMed: 20395557]

147. Liu G, et al. miR-21 mediates fibrogenic activation of pulmonary fibroblasts and lung fibrosis. J. Exp. Med. 2010; 207:1589-1597. [PubMed: 20643828]

148. Yang T, et al. miR-29 mediates TGFbeta1 induced extracellular matrix synthesis through activation of PI3K AKT pathway in human lung fibroblasts. J. Cell. Biochem. 2013; 114:13361342. [PubMed: 23238947]

149. Parker MW, et al. Fibrotic extracellular matrix activates a profibrotic positive feedback loop. J. Clin. Invest. 2014; 124:1622-1635. This study provides direct insight into the effect of fibrotic ECM on the upregulation of selected fibroblast genes that are targeted by miR-29 in response to the low expression of this miRNA by fibrotic ECM. These findings support an ECM-driven 
positive feedback loop that can redirect fibroblast ECM gene expression by reducing miR-29 expression. [PubMed: 24590289]

150. Jones PA, Issa JP, Baylin S. Targeting the cancer epigenome for therapy. Nat. Rev. Genet. 2016; 17:630-641. [PubMed: 27629931]

151. Huan C, et al. Methylation-mediated BMPER expression in fibroblast activation in vitro and lung fibrosis in mice in vivo. Sci. Rep. 2015; 5:14910. [PubMed: 26442443]

152. Neary R, Watson CJ, Baugh JA. Epigenetics and the overhealing wound: the role of DNA methylation in fibrosis. Fibrogenesis Tissue Repair. 2015; 8:18. [PubMed: 26435749]

153. Zahnow CA, et al. Inhibitors of DNA methylation, histone deacetylation, and histone demethylation: a perfect combination for cancer therapy. Adv. Cancer Res. 2016; 130:55-111. [PubMed: 27037751]

154. Korfei M, et al. Aberrant expression and activity of histone deacetylases in sporadic idiopathic pulmonary fibrosis. Thorax. 2015; 70:1022-1032. [PubMed: 26359372]

155. Sanders YY, et al. Histone deacetylase inhibition promotes fibroblast apoptosis and ameliorates pulmonary fibrosis in mice. Eur. Respir. J. 2014; 43:1448-1458. [PubMed: 24603818]

156. Rao SS, et al. Suberoylanilide hydroxamic acid attenuates paraquat-induced pulmonary fibrosis by preventing Smad7 from deacetylation in rats. J. Thorac. Dis. 2016; 8:2485-2494. [PubMed: 27747000]

157. Khan S, Ahirwar K, Jena G. Anti-fibrotic effects of valproic acid: role of HDAC inhibition and associated mechanisms. Epigenomics. 2016; 8:1087-1101. [PubMed: 27411759]

158. Kawaoka, K., et al. Valproic acid attenuates renal fibrosis through the induction of autophagy. Clin. Exp. Nephrol. 2016. http://dx.doi.org/10.1007/s10157-016-1365-6

159. Seet LF, et al. Valproic acid suppresses collagen by selective regulation of Smads in conjunctival fibrosis. J. Mol. Med. (Berl.). 2016; 94:321-334. [PubMed: 26507880]

160. Tough DF, Tak PP, Tarakhovsky A, Prinjha RK. Epigenetic drug discovery: breaking through the immune barrier. Nat. Rev. Drug Discov. 2016; 15:835-853. [PubMed: 27765940]

161. Yang S, et al. Participation of miR-200 in pulmonary fibrosis. Am. J. Pathol. 2012; 180:484-493. [PubMed: 22189082]

162. Xiao J, et al. miR-29 inhibits bleomycin-induced pulmonary fibrosis in mice. Mol. Ther. 2012; 20:1251-1260. [PubMed: 22395530]

163. Montgomery RL, et al. MicroRNA mimicry blocks pulmonary fibrosis. EMBO Mol. Med. 2014; 6:1347-1356. [PubMed: 25239947]

164. Das S, et al. MicroRNA-326 regulates profibrotic functions of transforming growth factor-beta in pulmonary fibrosis. Am. J. Respir. Cell Mol. Biol. 2014; 50:882-892. [PubMed: 24279830]

165. van der Ree MH, et al. Long-term safety and efficacy of microRNA-targeted therapy in chronic hepatitis C patients. Antiviral Res. 2014; 111:53-59. [PubMed: 25218783]

166. Korfei M, et al. Epithelial endoplasmic reticulum stress and apoptosis in sporadic idiopathic pulmonary fibrosis. Am. J. Respir. Crit. Care Med. 2008; 178:838-846. [PubMed: 18635891]

167. Torres-Gonzalez E, et al. Role of endoplasmic reticulum stress in age-related susceptibility to lung fibrosis. Am. J. Respir. Cell Mol. Biol. 2012; 46:748-756. [PubMed: 22227563]

168. Pereira ER, Frudd K, Awad W, Hendershot LM. Endoplasmic reticulum (ER) stress and hypoxia response pathways interact to potentiate hypoxia-inducible factor 1 (HIF-1) transcriptional activity on targets like vascular endothelial growth factor (VEGF). J. Biol. Chem. 2014; 289:3352-3364. [PubMed: 24347168]

169. Das I, et al. Preventing proteostasis diseases by selective inhibition of a phosphatase regulatory subunit. Science. 2015; 348:239-242. [PubMed: 25859045]

170. Feng HL, et al. Combined lithium and valproate treatment delays disease onset, reduces neurological deficits and prolongs survival in an amyotrophic lateral sclerosis mouse model. Neuroscience. 2008; 155:567-572. [PubMed: 18640245]

171. Sarkar S, Davies JE, Huang Z, Tunnacliffe A, Rubinsztein DC. Trehalose, a novel mTORindependent autophagy enhancer, accelerates the clearance of mutant huntingtin and alphasynuclein. J. Biol. Chem. 2007; 282:5641-5652. [PubMed: 17182613]

Nat Rev Drug Discov. Author manuscript; available in PMC 2018 April 30. 
172. Ozcan U, et al. Chemical chaperones reduce ER stress and restore glucose homeostasis in a mouse model of type 2 diabetes. Science. 2006; 313:1137-1140. [PubMed: 16931765]

173. Diamant S, Eliahu N, Rosenthal D, Goloubinoff P. Chemical chaperones regulate molecular chaperones in vitro and in cells under combined salt and heat stresses. J. Biol. Chem. 2001; 276:39586-39591. [PubMed: 11517217]

174. Keohane D, Schwartz J, Gundapaneni B, Stewart M, Amass L. Tafamidis delays disease progression in patients with early stage transthyretin familial amyloid polyneuropathy: additional supportive analyses from the pivotal trial. Amyloid. 2017; 24:30-36.

175. Mu TW, et al. Chemical and biological approaches synergize to ameliorate protein-folding diseases. Cell. 2008; 134:769-781. [PubMed: 18775310]

176. Mu TW, Fowler DM, Kelly JW. Partial restoration of mutant enzyme homeostasis in three distinct lysosomal storage disease cell lines by altering calcium homeostasis. PLoS Biol. 2008; 6:e26. [PubMed: 18254660]

177. Kusaczuk M, Bartoszewicz M, Cechowska-Pasko M. Phenylbutyric acid: simple structure multiple effects. Curr. Pharm. Des. 2015; 21:2147-2166. [PubMed: 25557635]

178. Zhao H, et al. Phenylbutyric acid inhibits epithelial-mesenchymal transition during bleomycininduced lung fibrosis. Toxicol. Lett. 2015; 232:213-220. [PubMed: 25455454]

179. Plate L, et al. Small molecule proteostasis regulators that reprogram the ER to reduce extracellular protein aggregation. eLife. 2016; 5:e15550. [PubMed: 27435961]

180. Romero, Y., et al. mTORC1 activation decreases autophagy in aging and idiopathic pulmonary fibrosis and contributes to apoptosis resistance in IPF fibroblasts. Aging Cell. 2016. http:// dx.doi.org/10.1111/acel.12514

181. Mora AL, Bueno M, Rojas M. Mitochondria in the spotlight of aging and idiopathic pulmonary fibrosis. J. Clin. Invest. 2017; 127:405-414. [PubMed: 28145905]

182. Frantz MC, Wipf P. Mitochondria as a target in treatment. Environ. Mol. Mutag. 2010; 51:462475.

183. Snow BJ, et al. A double-blind, placebo-controlled study to assess the mitochondria-targeted antioxidant MitoQ as a disease-modifying therapy in Parkinson's disease. Mov. Disord. 2010; 25:1670-1674. [PubMed: 20568096]

184. Rehman H, et al. The mitochondria-targeted antioxidant MitoQ attenuates liver fibrosis in mice. Int. J. Physiol., Pathophysiol. Pharmacol. 2016; 8:14-27. [PubMed: 27186319]

185. Jain M, et al. Mitochondrial reactive oxygen species regulate transforming growth factor-beta signaling. J. Biol. Chem. 2013; 288:770-777. [PubMed: 23204521]

186. Kim SJ, et al. Mitochondrial catalase overexpressed transgenic mice are protected against lung fibrosis in part via preventing alveolar epithelial cell mitochondrial DNA damage. Free Radic. Biol. Med. 2016; 101:482-490. [PubMed: 27840320]

187. Xun Z, et al. Targeting of XJB-5-131 to mitochondria suppresses oxidative DNA damage and motor decline in a mouse model of Huntington's disease. Cell Rep. 2012; 2:1137-1142. [PubMed: 23122961]

188. Nguyen TN, Padman BS, Lazarou M. Deciphering the molecular signals of PINK1/Parkin mitophagy. Trends Cell Biol. 2016; 26:733-744. [PubMed: 27291334]

189. Youle RJ, Narendra DP. Mechanisms of mitophagy. Nat. Rev. Mol. Cell Biol. 2011; 12:9-14. [PubMed: 21179058]

190. Narendra D, Walker JE, Youle R. Mitochondrial quality control mediated by PINK1 and Parkin: links to parkinsonism. Cold Spring Harb. Perspect. Biol. 2012; 4:a011338. [PubMed: 23125018]

191. Bueno M, et al. PINK1 deficiency impairs mitochondrial homeostasis and promotes lung fibrosis. J. Clin. Invest. 2015; 125:521-538. This study shows morphological and functional abnormalities in the mitochondria of AEC2s from IPF lungs. Mitochondrial abnormalities and dysfunction were found to increase with age and ER stress and were associated with the low expression of PINK1, a crucial regulator of mitochondrial homeostasis. [PubMed: 25562319]

192. Patel AS, et al. Epithelial cell mitochondrial dysfunction and PINK1 are induced by transforming growth factor beta1 in pulmonary fibrosis. PLoS ONE. 2015; 10:e0121246. [PubMed: 25785991]

193. Sosulski ML, et al. Deregulation of selective autophagy during aging and pulmonary fibrosis: the role of TGFbeta1. Aging Cell. 2015; 14:774-783. [PubMed: 26059457] 
194. Kobayashi K, et al. Involvement of PARK2 mediated mitophagy in idiopathic pulmonary fibrosis pathogenesis. J. Immunol. 2016; 197:504-516. [PubMed: 27279371]

195. Larson-Casey JL, Deshane JS, Ryan AJ, Thannickal VJ, Carter AB. Macrophage Akt1 kinasemediated mitophagy modulates apoptosis resistance and pulmonary fibrosis. Immunity. 2016; 44:582-596. [PubMed: 26921108]

196. Hertz NT, et al. A neo-substrate that amplifies catalytic activity of parkinson's disease-related kinase PINK1. Cell. 2013; 154:737-747. [PubMed: 23953109]

197. Axelrod FB, et al. Kinetin improves IKBKAP mRNA splicing in patients with familial dysautonomia. Pediatr. Res. 2011; 70:480-483. [PubMed: 21775922]

198. Shetty RS, et al. Specific correction of a splice defect in brain by nutritional supplementation. Hum. Mol. Genet. 2011; 20:4093-4101. [PubMed: 21821670]

199. Sundaresan NR, et al. SIRT3 blocks aging-associated tissue fibrosis in mice by deacetylating and activating glycogen synthase kinase 3beta. Mol. Cell. Biol. 2016; 36:678-692.

200. Kwon Y, Kim J, Lee CY, Kim H. Expression of SIRT1 and SIRT3 varies according to age in mice. Anat. Cell Biol. 2015; 48:54-61. [PubMed: 25806122]

201. Akamata K, et al. SIRT3 is attenuated in systemic sclerosis skin and lungs, and its pharmacologic activation mitigates organ fibrosis. Oncotarget. 2016; 7:69321-69336. [PubMed: 27732568]

202. Sosulski ML, Gongora R, Feghali-Bostwick C, Lasky JA, Sanchez CG. Sirtuin 3 deregulation promotes pulmonary fibrosis. J. Gerontol. A, Biol. Sci. Med. Sci. 2016; 72:595-602.

203. Bindu S, et al. SIRT3 blocks myofibroblast differentiation and pulmonary fibrosis by preventing mitochondrial DNA damage. Am. J. Physiol. Lung Cell. Mol. Physiol. 2017; 312:L68-L78. [PubMed: 27815257]

204. Cheng Y, et al. Interaction of Sirt3 with OGG1 contributes to repair of mitochondrial DNA and protects from apoptotic cell death under oxidative stress. Cell Death Dis. 2013; 4:e731. [PubMed: 23868064]

205. Kim SJ, et al. Mitochondria-targeted Ogg1 and aconitase-2 prevent oxidant-induced mitochondrial DNA damage in alveolar epithelial cells. J. Biol. Chem. 2014; 289:6165-6176. [PubMed: 24429287]

206. Lee YL, et al. Mitochondrial DNA damage initiates acute lung injury and multi-organ system failure evoked in rats by intra-tracheal pseudomonas aeruginosa. Shock. 2017; 48:54-60. [PubMed: 28125528]

207. Camacho-Pereira J, et al. CD38 dictates age-related NAD decline and mitochondrial dysfunction through an SIRT3 dependent mechanism. Cell Metab. 2016; 23:1127-1139. [PubMed: 27304511]

208. Haffner CD, et al. Discovery, synthesis, and biological evaluation of thiazoloquin(az)olin(on)es as potent CD38 inhibitors. J. Med. Chem. 2015; 58:3548-3571. [PubMed: 25828863]

209. Oh GS, et al. Increased cellular NAD+ level through NQO1 enzymatic action has protective effects on bleomycin-induced lung fibrosis in mice. Tuberc. Respir. Dis. (Seoul). 2016; 79:257266. [PubMed: 27790277]

210. Rojas M, et al. Bone marrow-derived mesenchymal stem cells in repair of the injured lung. Am. J. Respir. Cell Mol. Biol. 2005; 33:145-152. Initial study in mouse models of lung injury showing that MSCs are required for lung tissue repair after injury. [PubMed: 15891110]

211. Alvarez D, Levine M, Rojas M. Regenerative medicine in the treatment of idiopathic pulmonary fibrosis: current position. Stem Cells Cloning. 2015; 8:61-65. [PubMed: 25926746]

212. Wang W, et al. Intravenous administration of bone marrow mesenchymal stromal cells is safe for the lung in a chronic myocardial infarction model. Regen. Med. 2011; 6:179-190. [PubMed: 21391852]

213. Zanetti A, et al. Suspension-expansion of bone marrow results in small mesenchymal stem cells exhibiting increased transpulmonary passage following intravenous administration. Tissue Eng. Part C Methods. 2015; 21:683-692. [PubMed: 25567723]

214. Lu H, et al. Pulmonary retention of adipose stromal cells following intravenous delivery is markedly altered in the presence of ARDS. Cell Transplant. 2016; 25:1635-1643. [PubMed: 26609693] 
215. Ortiz LA, et al. Mesenchymal stem cell engraftment in lung is enhanced in response to bleomycin exposure and ameliorates its fibrotic effects. Proc. Natl Acad. Sci. USA. 2003; 100:8407-8411. [PubMed: 12815096]

216. Chambers DC, et al. A phase $1 \mathrm{~b}$ study of placenta-derived mesenchymal stromal cells in patients with idiopathic pulmonary fibrosis. Respirology. 2014; 19:1013-1018. [PubMed: 25039426]

217. Glassberg MK, et al. Allogeneic human mesenchymal stem cells in patients with idiopathic pulmonary fibrosis via intravenous delivery (AETHER): a phase I, safety, clinical trial. Chest. 2016; 151:971-981. [PubMed: 27890713]

218. Dadrich M, et al. Combined inhibition of TGFbeta and PDGF signaling attenuates radiationinduced pulmonary fibrosis. Oncoimmunology. 2016; 5:e1123366. [PubMed: 27467922]

219. Oldham JM, et al. TOLLIP, MUC5B, and the response to N Acetylcysteine among individuals with idiopathic pulmonary fibrosis. Am. J. Respir. Crit. Care Med. 2015; 192:1475-1482. [PubMed: 26331942]

220. Raghu G, et al. FG-3019 anti-connective tissue growth factor monoclonal antibody: results of an open-label clinical trial in idiopathic pulmonary fibrosis. Eur. Respir. J. 2016; 47:1481-1491. [PubMed: 26965296]

221. Wilkes DS, et al. Oral immunotherapy with type V collagen in idiopathic pulmonary fibrosis. Eur. Respir. J. 2015; 45:1393-1402. [PubMed: 25614165]

222. Couluris M, et al. Treatment of idiopathic pulmonary fibrosis with losartan: a pilot project. Lung. 2012; 190:523-527. [PubMed: 22810758]

223. van den Blink B, et al. Recombinant human pentraxin-2 therapy in patients with idiopathic pulmonary fibrosis: safety, pharmacokinetics and exploratory efficacy. Eur. Respir. J. 2016; 47:889-897. [PubMed: 26869678]

224. Raghu G, et al. CC chemokine ligand 2 inhibition in idiopathic pulmonary fibrosis: a phase 2 trial of carlumab. Eur. Respir. J. 2015; 46:1740-1750. [PubMed: 26493793]

225. van der Velden JL, et al. JNK inhibition reduces lung remodeling and pulmonary fibrotic systemic markers. Clin. Transl Med. 2016; 5:36. [PubMed: 27590145]

226. Raghu G, et al. Efficacy of simtuzumab versus placebo in patients with idiopathic pulmonary fibrosis: a randomised, double-blind, controlled, phase 2 trial. Lancet Respir. Med. 2017; 5:2232. [PubMed: 27939076]

227. Parker, JM., et al. Phase 2 randomized controlled study of tralokinumab in subjects with idiopathic pulmonary fibrosis. Am. J. Respir. Crit. Care Med. 2017. http://dx.doi.org/10.1164/ rccm.201704-0784OC 

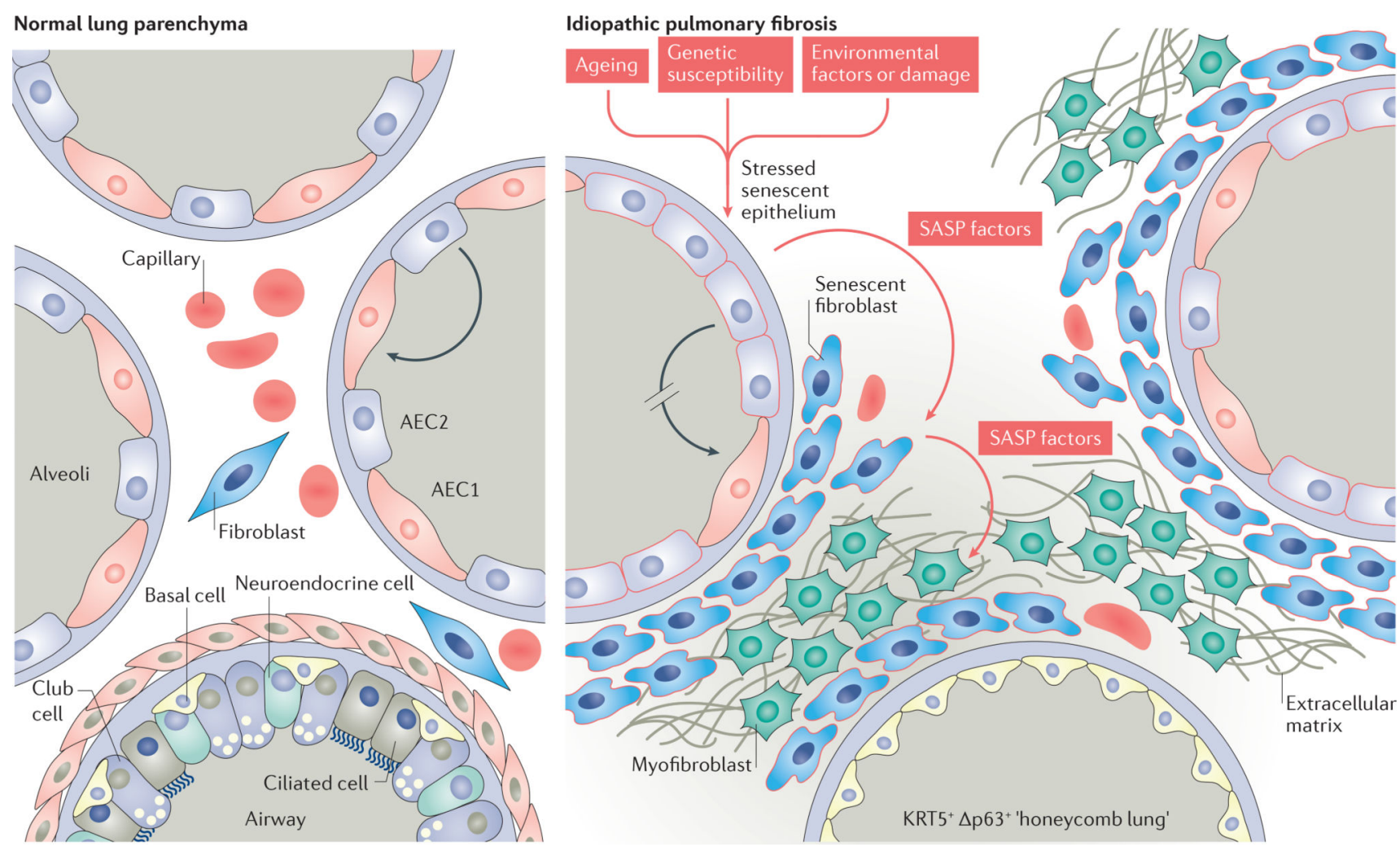

Figure 1. Model of idiopathic pulmonary fibrosis pathogenesis

Genetic predisposition, age-related cell perturbations and environmental exposures increase susceptibility to epithelial lung injury as they reduce the capacity of the lung to regenerate and to respond to stress. Epithelial cells show several markers of stress, activation and senescence, including the reactivation of embryonic pathways. In lungs with idiopathic pulmonary fibrosis (IPF), progenitor $\mathrm{KRT}^{+} \Delta \mathrm{p}^{+} 3^{+}$lung epithelial cells fail to regenerate alveolar epithelial type 2 cells (AEC2s) and this event promotes the formation of the characteristic pathology of IPF known as 'honeycomb lung'. Persistent aberrant activation and senescence of the epithelium leads to the hyperactive secretion of a set of pro-fibrotic growth factors, chemokines and angiostatic, procoagulant mediators collectively known as senescence-associated secretory phenotype (SASP) factors. SASP factors result in abnormal wound healing that is characterized by dysregulated crosstalk between the epithelium and the mesenchymal cells and by the accumulation of myofibroblasts. Fibroblasts and myofibroblasts in the IPF lung present a stressed and senescent phenotype, including resistance to apoptosis and exaggerated production of extracellular matrix components. Increased matrix stiffness generates changes in the niche that affect the behaviour of the fibroblasts and epithelial cells, thus causing irreversible damage and fibrosis. 
Phase 3

\section{Pirfenidone}

Nintedanib

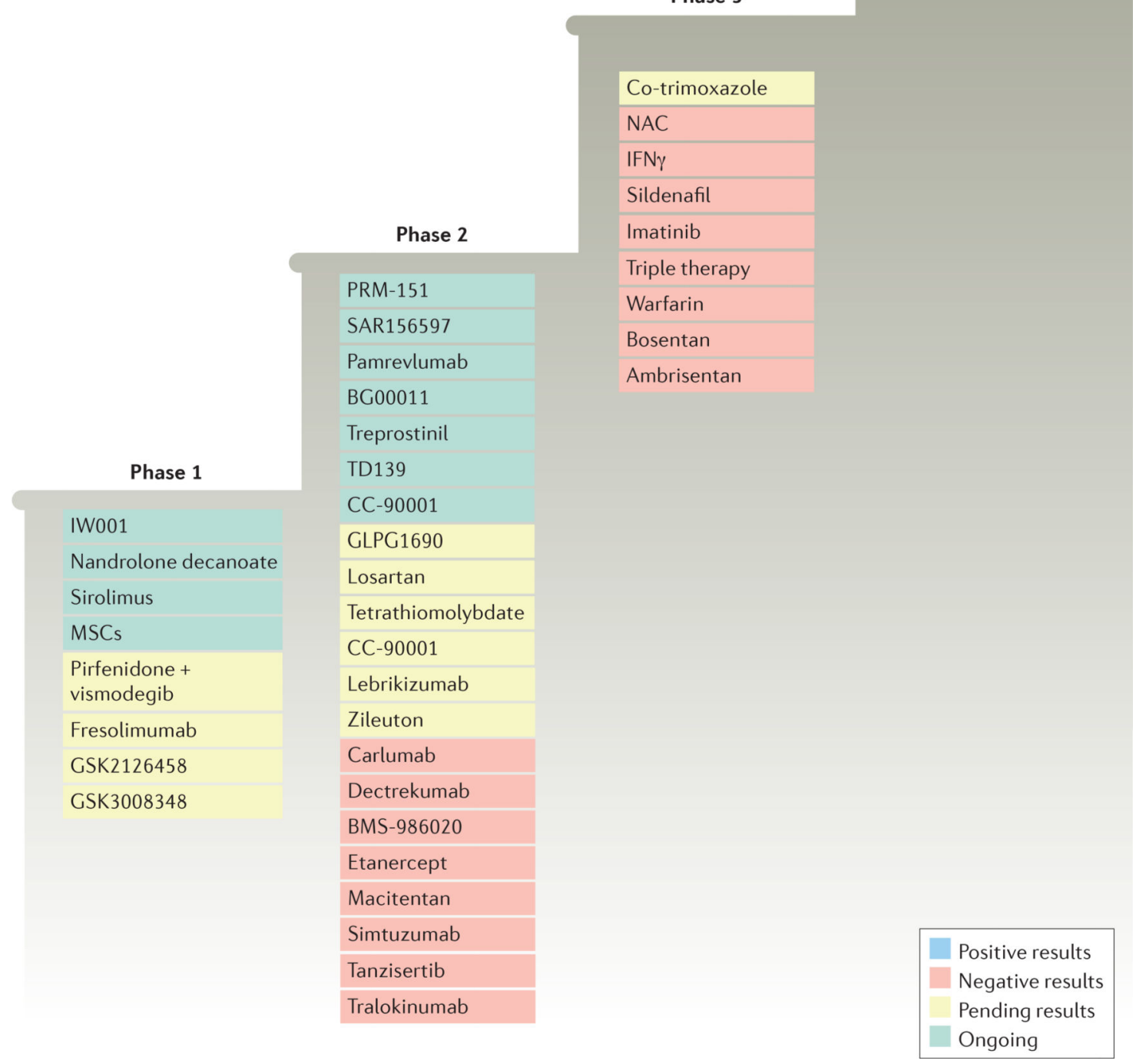

Figure 2. Overview of the main clinical trials focused on idiopathic pulmonary fibrosis Pharmacological compounds in clinical studies are shown according to the highest phase of clinical trial. Approved drugs are shown in blue. Studies with published negative results are shown in red. Ongoing studies with partial results are shown in green and those with pending data are shown in yellow. The triple therapy consists of prednisone, azathioprine and NAC. MSCs, mesenchymal stem cells; IFN $\gamma$, interferon- $\gamma$; NAC, $N$-acetyl-L-cysteine. 
Clearance of senescent cells

- Apoptosis modulator (navitoclax)

- Tyrosine kinase inhibitor (dasatinib)

- PI3K inhibitor (quercetin)

- p53 inhibitors

- Rupatadine

- NOX4 inhibitors

Mitochondria-targeted therapies

- Antioxidant scavengers

- SIRT3 agonist

- mtDNA repair enzymes

- Activators of mitophagy

- CD38 inhibitors

Activation of autophagy

- PI3K and mTOR inhibitors
Activation of proteostasis

- Pharmacological chaperone

- Inhibitors of $\mathrm{Ca}^{2+}$ mobilization

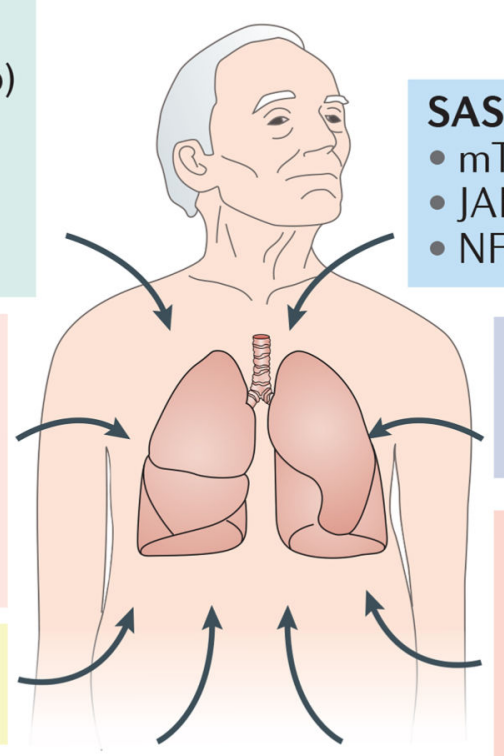

SASP inhibition

- mTOR inhibitor (rapamycin)

- JAK or STAT inhibitors

- NF-KB inhibitors
Stem cell therapies

- Heterologous young donors

Targeting the epigenome

- $5^{\prime}$-azacytidine

- Antagomir miR-21

- HDAC inhibitor (vorinostat)

Figure 3. Selected emerging therapeutic interventions that target age-related cell perturbations in lung fibrosis

Novel therapies for age-related diseases target key cellular processes in ageing cells.

Senolytic drugs include dasatinib, quercetin and navitoclax. Dasatinib and quercetin inhibit tyrosine kinases, and navitoclax inhibits anti-apoptotic family members of the B cell lymphoma 2 (BCL-2) protein family. The secretory associated senescence phenotype (SASP) is regulated by mechanistic target of rapamycin (mTOR), and mTOR inhibitors such as rapamycin can reduce the presence of SASP factors in senescent fibroblasts. mTOR inhibitors also promote autophagy and the apoptosis of fibroblasts in lungs with idiopathic pulmonary fibrosis (IPF). Rupatadine has also been shown to reduce cellular senescence and, potentially, SASP by preventing the activation of the $\mathrm{p} 53-\mathrm{p} 21$ pathway and by attenuating the expression of CCAAT/enhancer-binding protein- $\beta$ (C/EBP $\beta)$, a positive modulator of SASP. Inhibitors of the nuclear factor (NF)- $\kappa$ B signalling pathway inhibit SASP. Pharmacological chaperones, inhibitors of $\mathrm{Ca}^{2+}$ mobilization and the osmolytic compound 4-phenyl butyric acid (4-PBA) can rebalance proteostasis. Several therapeutic strategies are under development to improve mitochondrial function, including MitoQ and small molecules such as XBJ-5-131 that act as antioxidants and radical scavengers. Specific alterations found in the cells of IPF lungs suggest that activators of sirtuin 3 (SIRT3), inducers of mitophagy and methods to increase levels of mitochondrial DNA (mtDNA) repair enzymes might have beneficial therapeutic effects. Oestrogen receptor modulators such as raloxifene, as well as androgens, have been used to induce telomerase activity and to increase telomere length, although further studies are needed. HDAC, histone deacetylase; JAK, Janus kinase; miR-21, microRNA-21; NOX4, NADPH oxidase 4; PI3K, phosphoinositide 3-kinase; STAT, signal transducer and activator of transcription. 
Table 1

Selected novel drug candidates for idiopathic pulmonary fibrosis

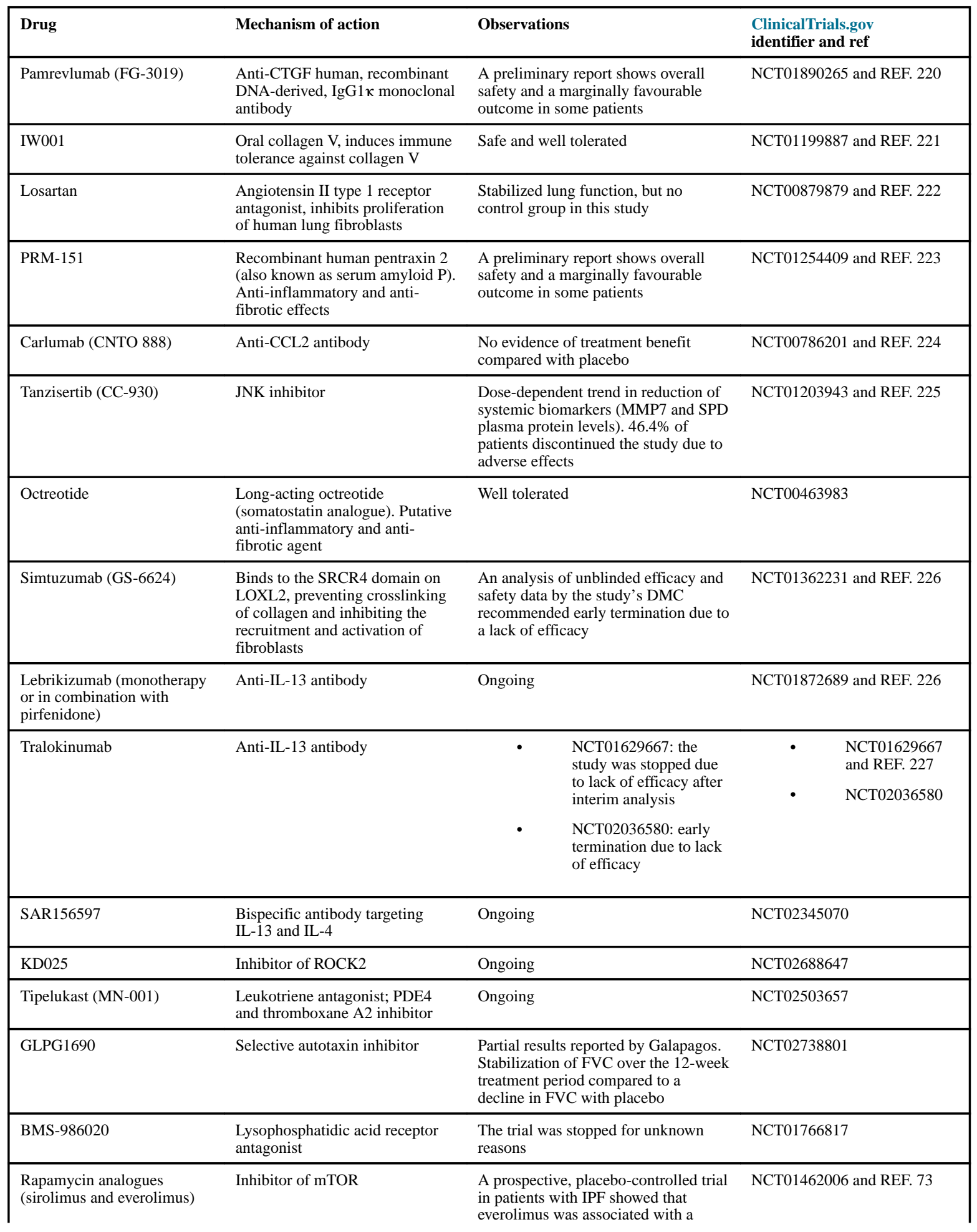

Nat Rev Drug Discov. Author manuscript; available in PMC 2018 April 30. 


\begin{tabular}{|llll|}
\hline Drug & Mechanism of action & Observations & $\begin{array}{l}\text { ClinicalTrials.gov } \\
\text { identifier and ref }\end{array}$ \\
\hline & & $\begin{array}{l}\text { greater rate of decrease in lung } \\
\text { function and disease progression }\end{array}$ & \\
\hline GSK2126458 & $\begin{array}{l}\text { Selective pyridyl sulfonamide } \\
\text { inhibitor of class 1 isozymes of } \\
\text { PI3K and mTOR }\end{array}$ & Completed; no results reported & NCT01725139 \\
\hline PBI-4050 & $\begin{array}{l}\text { Reduces the production of } \\
\text { TGFß1, CTGF, IL-23, p19 and } \\
\text { IL-6 }\end{array}$ & Completed; no results reported & NCT02538536 \\
\hline Rituximab & $\begin{array}{l}\text { Chimeric anti-CD20 monoclonal } \\
\text { antibody }\end{array}$ & Ongoing & NCT01969409 \\
\hline Inhaled TD139 & Galectin-3 inhibitor & $\begin{array}{l}\text { Completed; results are not published. } \\
\text { Galecto Biotech reports 24 patients } \\
\text { treated with TD139 or placebo for 2 } \\
\text { weeks }\end{array}$ & NCT02257177 \\
\hline Nandrolone decanoate & $\begin{array}{l}\text { Synthetic androgen; decreases } \\
\text { telomere attrition }\end{array}$ & Ongoing & NCT02055456 \\
\hline Vismodegib and pirfenidone & $\begin{array}{l}\text { Vismodegib is a Hedgehog } \\
\text { pathway inhibitor }\end{array}$ & Completed; no results reported & NCT02648048 \\
\hline
\end{tabular}

CCL2, CC motif chemokine 2; CTGF, connective tissue growth factor; DMC, data monitoring committee; FVC, forced vital capacity; IPF, idiopathic pulmonary fibrosis; JNK, JUN N-terminal kinase; LOXL2, Lysyl oxidase homolog 2; MMP7, matrix metalloproteinase 7; mTOR, mechanistic target of rapamycin; PDE4, phosphodiesterase 4; PI3K, phosphoinositide 3-kinase; ROCK2, Rho-associated protein kinase 2; SPD, surfactant protein D; SRCR4, scavenger receptor cysteine-rich 4; TGF $\beta 1$, transforming growth factor $\beta 1$. 